\title{
Resistance to the nucleotide analogue cidofovir in HPV(+) cells: a multifactorial process involving UMP/CMP kinase 1
}

\author{
Dimitri Topalis ${ }^{1}$, Tatiane C. Nogueira ${ }^{1, *}$, Tim De Schutter ${ }^{1, *}$, Chahrazade El Amri ${ }^{2}$, \\ Marcela Krečmerová ${ }^{3}$, Lieve Naesens ${ }^{1}$, Jan Balzarini ${ }^{1}$, Graciela Andrei ${ }^{1}$, Robert \\ Snoeck ${ }^{1}$ \\ ${ }^{1}$ Rega Institute for Medical Research, KU Leuven, 3000 Leuven, Belgium \\ ${ }^{2}$ Sorbonne Universités, UPMC University Paris 06, UMR 8256, B2A, Biological Adaptation and Ageing, Integrated Cellular \\ Ageing and Inflammation, Molecular and Functional Enzymology, Paris, 75252 Paris Cedex 05, France \\ ${ }^{3}$ Institute of Organic Chemistry and Biochemistry, Academy of Sciences of The Czech Republic, v.v.i., CZ-166 10 Prague 6, \\ Czech Republic \\ *These authors have contributed equally to this work
}

Correspondence to: Dimitri Topalis, e-mail: dimitrios.topalis@rega.kuleuven.be

Keywords: human papillomavirus, cervical carcinoma, UMP-CMP kinase, cidofovir, NTP metabolism

Received: July 09, 2015

Accepted: January 05, 2016

Published: January 25, 2016

\section{ABSTRACT}

Human papillomavirus (HPV) is responsible for cervical cancer, and its role in head and neck carcinoma has been reported. No drug is approved for the treatment of HPV-related diseases but cidofovir (CDV) exhibits selective antiproliferative activity.

In this study, we analyzed the effects of CDV-resistance (CDVR) in two HPV(+) $\left(\mathrm{SiHa}_{\mathrm{CDV}}\right.$ and $\left.\mathrm{HeLa}_{\mathrm{CDV}}\right)$ and one $\mathrm{HPV}(-)\left(\mathrm{HaCaT}_{\mathrm{CDV}}\right)$ tumor cell lines. Quantification of CDV metabolites and analysis of the sensitivity profile to chemotherapeutics was performed. Transporters expression related to multidrug-resistance (MRP2, P-gp, BCRP) was also investigated.

Alterations of CDV metabolism in $\mathrm{SiHa}_{\mathrm{CDV}}$ and $\mathrm{HeLa}_{\mathrm{CDV}}$, but not in $\mathrm{HaCaT}_{\mathrm{CDV}}$, emerged via impairment of UMP/CMPK1 activity. Mutations (P64T and R134M) as well as down-regulation of UMP/CMPK1 expression were observed in $\mathrm{SiHa}_{\mathrm{CDV}}$ and $\mathrm{HeLa}_{\mathrm{CDV}}$, respectively. Altered transporters expression in $\mathrm{SiHa}_{\mathrm{CDV}}$ and/or $\mathrm{HeLa}_{\mathrm{CDV}}$, but not in HaCaTCDV, was also noted.

Taken together, these results indicate that $\operatorname{CDV}^{\mathrm{R}}$ in $\mathrm{HPV}(+)$ tumor cells is a multifactorial process.

\section{INTRODUCTION}

Cidofovir (CDV) is an acyclic nucleoside phosphonate (ANP) with broad spectrum anti-DNA virus activity [1]. Its intravenous form is approved for therapy of cytomegalovirus retinitis in AIDS patients [2]. CDV is also used off-label for treatment of several diseases associated with herpesviruses other than cytomegalovirus, comprising adeno-, pox-, polyoma-, and papillomaviruses [3-6]. Besides its well-characterized antiviral activity, CDV is active as an antitumor agent in several animal models, including human cervical carcinoma xenografts in athymic nude mice [7-10]. CDV inhibitory effect on tumor growth has been attributed to its recognition by cellular DNA polymerases and incorporation into genomic DNA causing DNA breaks and/or apoptosis induction [11]. The higher sensitivity of cervical carcinoma cells carrying the human papillomavirus (HPV) genome, i.e. SiHa [HPV16 (+)] and HeLa [HPV18 (+)] to CDV compared to primary human keratinocytes (PHKs) has been explained by the differential response of tumor cells and normal cells to DNA damage $[12,13]$.

The cytosolic UMP/CMP kinase 1, a key enzyme in the activation of antiviral and anticancer drugs, catalyzes the phosphorylation of (d)CMP analogues to their diphosphate forms [14-16]. 2'-deoxycytidine (dC) (i.e. lamivudine and emtricitabine) or 2'-deoxycytidine monophosphate (dCMP) (i.e. CDV) analogues require phosphorylation by UMP/CMPK1 [17]. The first and 
last phosphorylation steps of cytidine 2'-deoxynucleoside analogues are catalyzed, respectively, by deoxycytidine kinase (dCK) and nucleoside diphosphate kinase (NDPK) [17]. Similarly, the anticancer agents cytarabine (araC) and gemcitabine $(\mathrm{dFdC})$ are activated by UMP/CMPK1 following prior conversion to their $5^{\prime}$-monophosphate forms by dCK [18]. The mitochondrial form of UMP/ CMPK (i.e. UMP/CMPK2) possesses distinct substrate specificity since it recognizes dUMP and dCMP as best phosphate acceptors while the cytosolic form preferentially phosphorylates CMP and UMP [19]. Both enzymes are also able to phosphorylate nucleotide analogues such as the monophosphate forms of the anti-cancer agents araC-MP and dFdC-MP [15, 18-20].

Failure to anticancer therapy is often due to drug-resistance because of emergence of mutations in the cellular target or in one of the activating enzymes, multidrug-resistance (MDR) events leading to efflux of the active metabolite, or activation of DNA repair pathways [21-23]. Several drug-resistance mechanisms for araC or $\mathrm{dFdC}$ were described, including i) deamination by cytidine deaminase which converts araC into the inactive metabolite araU [24, 25], ii) down-regulation of the equilibrative nucleoside transporter (hENT1), the major carrier for araC and $\mathrm{dFdC}$ uptake [26], iii) circumvention of dCK-dependent araC and $\mathrm{dFdC}$ phosphorylation by down-regulation of $\mathrm{dCK}$ expression or point mutations leading to weaker activation of araC and $\mathrm{dFdC}[27,28]$.

Unlike araC and $\mathrm{dFdC}, \mathrm{CDV}$ intracellular uptake occurs via fluid-phase endocytosis and is independent of hENT [29]. In primary kidney tubular cells, CDV uptake is mediated through the organic anion transporters OAT1, and to a lesser extent OAT3. CDV activation is independent from dCK since CDV bears a phosphonate moiety at its methoxyhydroxypropyl part, bypassing then the initial phosphorylation by a nucleoside kinase. Thus, $\mathrm{CDV}$-resistance $\left(\mathrm{CDV}^{\mathrm{R}}\right)$ mechanisms are expected to be different from those described for cytosine nucleoside analogues.

In this study, we investigated the impact of $\mathrm{CDV}^{\mathrm{R}}$ on UMP/CMPK1 and on nucleoside metabolism, in particular on CTP and UTP biosynthesis. Three cell lines [two HPV (+) (SiHa and HeLa) and one HPV(-) $(\mathrm{HaCaT})]$ were selected in vitro for resistance to $\mathrm{CDV}$ and were denoted $\mathrm{SiHa}_{\mathrm{CDV}}, \mathrm{HeLa}_{\mathrm{CDV}}$ and $\mathrm{HaCaT}_{\mathrm{CDV}}$ The susceptibility of these cell lines to several chemotherapeutics was assessed, as well as, the emergence of multi-drug-resistance mechanisms through upregulation of specific transporters. The metabolism of CDV, and in particular its incorporation into genomic DNA, was also investigated in these $\mathrm{CDV}^{\mathrm{R}}$ cell lines.

\section{RESULTS}

\section{Growth rate of $\mathrm{CDV}^{\mathrm{R}}$ cells and sensitivity to ANPs}

$\mathrm{SiHa}_{\mathrm{CDV}}$ and $\mathrm{HeLa}_{\mathrm{CDV}}$ had a significantly slower growth rate than parental cells [doubling time (DT) of $36 \mathrm{~h}$ versus $22 \mathrm{~h}$ and $24 \mathrm{~h}$ versus $21 \mathrm{~h}$, respectively] (Figure S1). In contrast, cellular growth rates were not significantly different between $\mathrm{HaCaT}_{\text {parental }}$ and $\mathrm{HaCaT}_{\mathrm{CDV}}$ cells (i.e. DT of $26 \mathrm{~h}$ and $23 \mathrm{~h}$, respectively).

To determine the sensitivity of parental and $\mathrm{CDV}^{\mathrm{R}}$ cells to $\mathrm{CDV}, \mathrm{CC}_{50}$ 's following 7 days of incubation in the presence of the drug were evaluated (Figure 1). The highest fold-resistance (FR) was found for $\mathrm{SiHa}_{\mathrm{CDV}}(>133)$ while for $\mathrm{HeLa}_{\mathrm{CDV}}$ and $\mathrm{HaCaT}_{\mathrm{CDV}}$, FR values were of $>18$ and $>49$, respectively.

The sensitivity of $\mathrm{CDV}^{\mathrm{R}}$ cells to several chemotherapeutics was also investigated (Figure 1). Five different levels of resistance/hypersensitivity were recognized when considering a statistical significant difference $(p<0.05)$ between compounds' $\mathrm{CC}_{50}$ values for parental and $\mathrm{CDV}^{\mathrm{R}}$ cells together with FR values: high resistance $(F R \geq 10)$, moderate resistance $(5 \leq F R<10)$, mild resistance $(2.0 \leq \mathrm{FR}<5)$, no resistance $(0.4<\mathrm{FR}<2.0)$ and hypersensitivity $(0.4 \geq \mathrm{FR})$.

Regarding ANPs, $\mathrm{SiHa}_{\mathrm{CDV}}$ cells were found to be highly resistant to HPMP derivatives with a FR in the range of 10 to 133 and moderate resistant to PME derivatives (Figure 1). For $\mathrm{HeLa}_{\mathrm{CDV}}$ cells, high resistance was observed for cHPMPC, moderate resistance to HPMPO-DAPY, HPMP-5azaC, cHPMP-azaC and HPMPA, while mild resistance was found for 3-deaza-HPMPA, PMEA, PMEG and cPr-PMEDAP. $\mathrm{HaCaT}_{\mathrm{CDV}}$ was highly resistant to cHPMPC, HPMPA, cHPMPA, HPMP-5azaC, moderately resistant to cHPMP-5azaC and exhibited mild resistance to HPMPDAP and HPMPO-DAPY. Hypersensitivity to PMEDAP and PMEA was observed for $\mathrm{HaCaT}_{\mathrm{CDV}}$.

\section{Sensitivity of $\mathrm{CDV}^{\mathrm{R}}$ cells to distinct chemotherapeutic agents}

The results for other chemotherapeutics, structurally unrelated to ANPs but possessing antiproliferative activity against several type of cancers, are shown in Figure 1. Moderate resistance was observed against fludarabine and mild resistance against cytarabine, camptothecin, SN-38 and topotecan, while hypersensitivity was demonstrated to docetaxel when tested on the $\mathrm{SiHa}_{\mathrm{CDV}} \cdot \mathrm{HeLa}_{\mathrm{CDV}}$ was found to have high resistance to fludarabine and mild resistance to cytarabine, while hypersensitivity was found for daunorubicin. $\mathrm{HaCaT}_{\mathrm{CDV}}$ was shown to be hypersensitive to docetaxel, 5-fluorouracil and cytarabine. 
Microarray data highlighted some genes likely involved in hypersensitivity or resistance to different chemotherapeutics in $\mathrm{CDV}^{\mathrm{R}}$ cells. For some of the differentially expressed genes, in particular those coding for proteins involved in uptake/efflux of different chemotherapeutics, enzymes required for their activation or catabolism and their target proteins, protein level variations were indicated (Table 1).
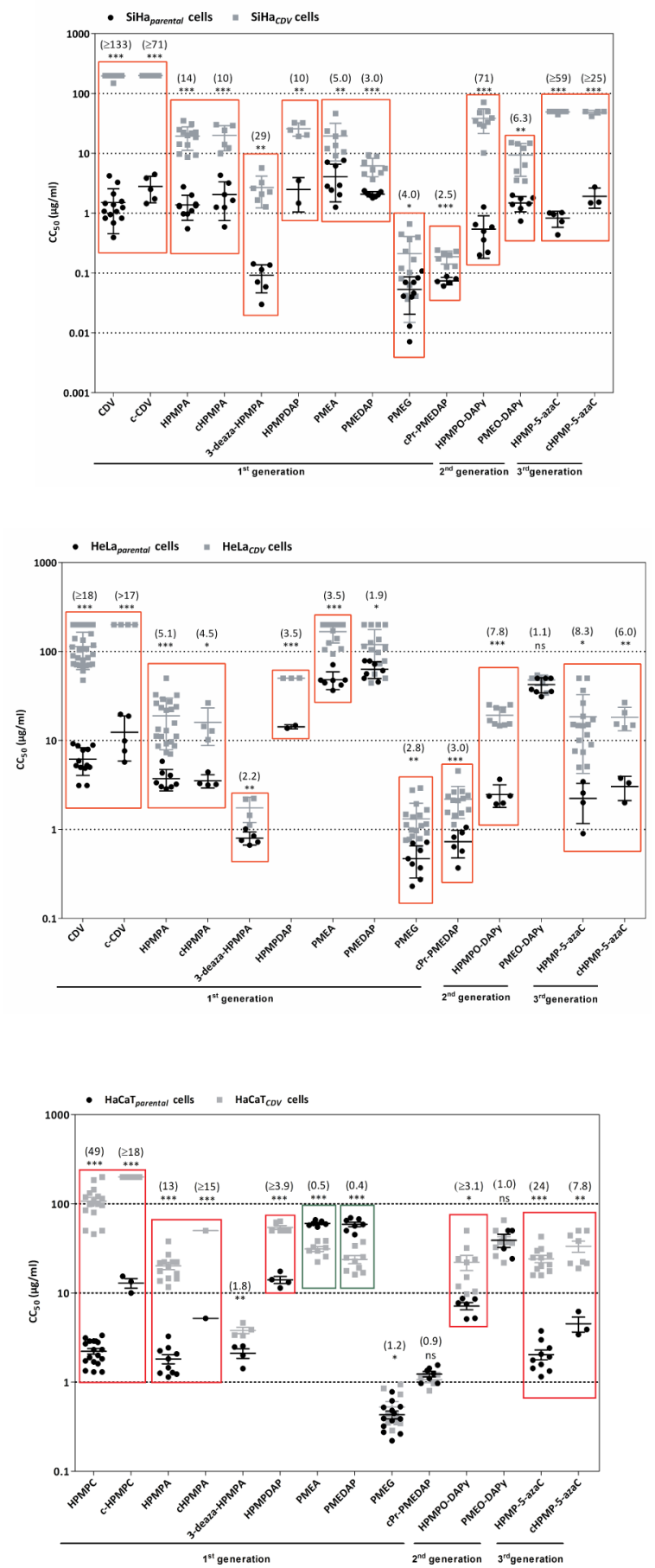

In $\mathrm{SiHa}_{\mathrm{CDV}}$, cross-resistance to camptothecin, $\mathrm{SN}-38$ and topotecan can be explained via up-regulation of efflux pump genes $A B C G 2$ (BCRP) and/or $A B C C 2$ (MRP2) (Table 1), as demonstrated in previous studies with different malignant cells [30-32]. Down-regulation of influx transporters SLC22A6 (OAT1) and SLC29A1 (ENT1), and decreased expression of phosphorylating enzymes ( $A K 2$ and $C M P K 1)$, may be responsible for
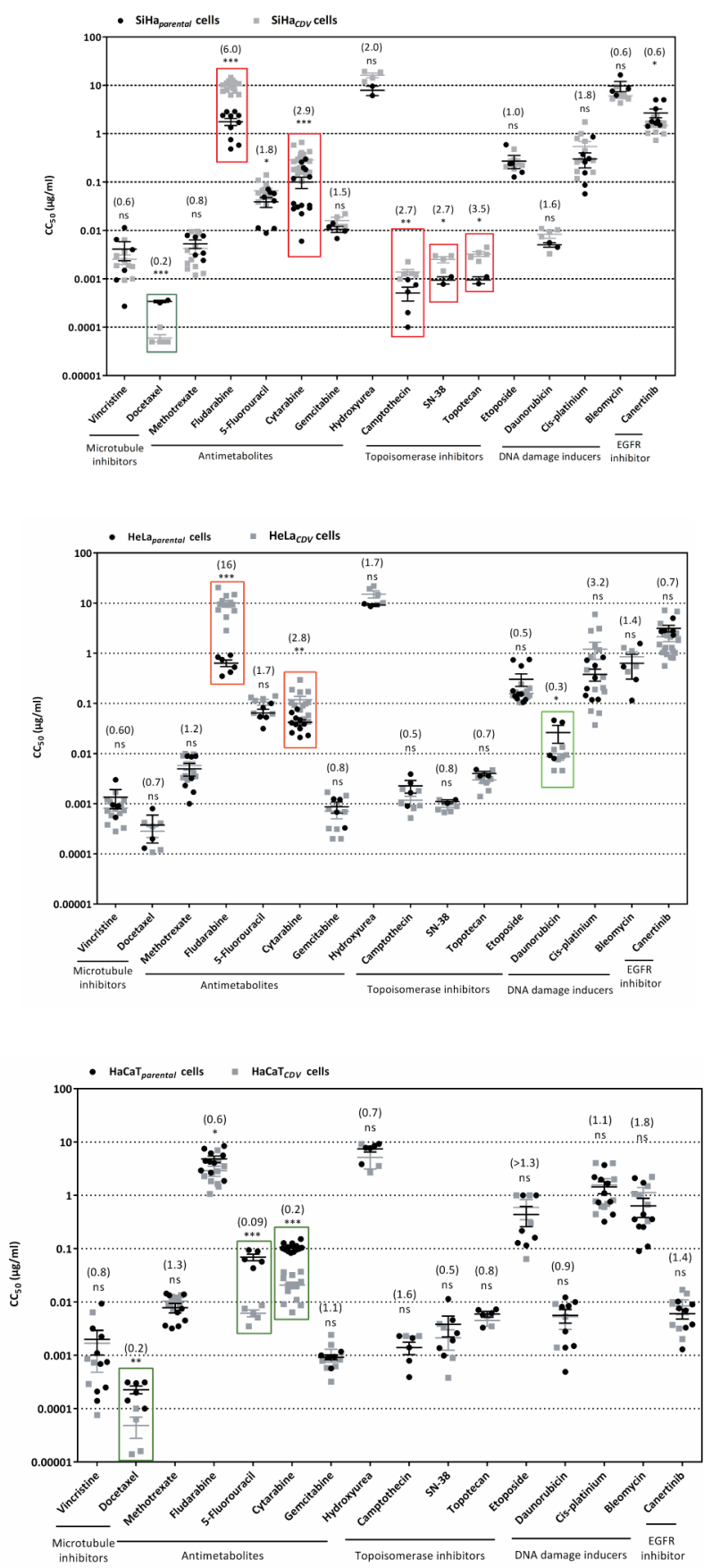

Figure 1: Sensitivity of parental and $\mathrm{CDV}^{\mathrm{R}} \mathrm{SiHa}$, HeLa and HaCaT cells to different ANPs and other chemotherapeutics. Between parentheses are presented the fold resistance values for each compound. 
Table 1: Genes that might be involved in resistance or hypersensitivity to antiproliferative drugs in SiHa (A), HeLa (B) and HaCaT (C)

\begin{tabular}{|c|c|c|c|c|c|c|}
\hline $\mathbf{A}$ & Docetaxel & Fludarabine & Cytarabine & Camptothecin & SN-38 & Topotecan \\
\hline $\mathrm{SiHa}_{\mathrm{CDV}}$ & $\begin{array}{l}\text { Hypersensitivity } \\
M A P 2(-1.30) \\
M A P T(-1.00)\end{array}$ & $\begin{array}{l}\text { Resistance } \\
S L C 29 A 1 \\
(-1.59)\end{array}$ & $\begin{array}{l}\text { Resistance } \\
\text { CMPK1 } \\
\text { (mutations) } \\
\text { ( } \downarrow \text { protein) } \\
\text { NT5E }(+2.20)\end{array}$ & $\begin{array}{l}\text { Resistance } \\
A B C C 2(+2.17) \\
(\uparrow \text { protein }) \\
A B C G 2(+1.02) \\
\text { ( } \uparrow \text { protein) }\end{array}$ & $\begin{array}{l}\text { Resistance } \\
A B C C 2(+2.17) \\
(\uparrow \text { protein) } \\
A B C G 2(+1.02) \\
\text { ( } \uparrow \text { protein) }\end{array}$ & $\begin{array}{l}\text { Resistance } \\
A B C G 2(+1.02) \\
(\uparrow \text { protein }) \\
T O P 2 A(+1.02)\end{array}$ \\
\hline
\end{tabular}

\begin{tabular}{|l|l|l|l|}
\hline \multicolumn{2}{c}{ B } & \multicolumn{1}{c}{ Cytarabine } & \multicolumn{1}{c}{ Daunorubicin } \\
\hline & Resistance & Resistance & Hypersensitivity \\
& AK2 $(-1.19)$ & $C M P K 1(-1.29)$ & $?$ \\
HeLa $_{\text {CDV }}$ & POLE4 $(+1.15)$ & $(\downarrow$ protein $)$ & genes involved in DNA damage \\
& & & response \\
& & & \\
\hline
\end{tabular}

\begin{tabular}{|c|c|c|c|}
\hline $\mathbf{C}$ & Docetaxel & 5-Fluorouracil & Cytarabine \\
\hline $\mathrm{HaCaT}_{\mathrm{CDV}}$ & $\begin{array}{l}\text { Hypersensitivity } \\
\text { TUBB } 2 A(-1.01) \\
\text { KIF1C }(-1.24) \\
\text { KIF3C }(-1.27) \\
A B C C 3(-2.86) \\
\text { CYP1B1 }(-1.05) \\
\text { CYP3A7 }(-2.77)\end{array}$ & $\begin{array}{l}\text { Hypersensitivity } \\
S L C 29 A 2(+1.47) \\
A B C C 3(-2.86)\end{array}$ & $\begin{array}{l}\text { Hypersensitivity } \\
C M P K 1(-0.31) \\
(\approx \text { protein }) \\
\text { NT5E }(-1.00)\end{array}$ \\
\hline
\end{tabular}

Abbreviations: TUBB2A: tubulin beta 2A, MAP2: microtubule associated protein 2, MAPT: microtubule associated protein tau, $K I F 1 C$ : kinesin like protein 1C, KIF3C: kinesin like protein 3C, CYP1B1: cytochrome P450 1B1, CYP3A7: cytochrome P450 3A7, SLC29A1/A2: equilibrative nucleoside transporter 1/2, AK2: adenylate kinase 2, POLE4: DNA polymerase epsilon subunit 4, $A B C G 2$ : ATP binding cassette type G2, NT5E: ecto-5'-nucleotidase (CD73), CMPK1: UMP/CMP kinase 1, TOP2A: topoisomerase II A, $A B C C 2 / 3$ : ATP binding cassette type $\mathrm{C} 2 / \mathrm{C} 3$.

Note: Between parentheses are shown the fold change $\left(\log _{\mathrm{N}} \mathrm{FC}\right)$ of the upregulated $(+)$ and downregulated $(-)$ genes. For resistance or hypersensitivity consideration, the cut-off was set to 2.5 (for resistance) and 0.4 (for hypersensitivity). $\uparrow, \downarrow$ and $\approx$ symbolize, respectively, increase, decrease and unchanged level of protein expression as observed by Western blot.

cross-resistance to fludarabine and cytarabine, respectively.

In $\mathrm{HeLa}_{\mathrm{CDV}}$, up-regulation of the DNA polymerase $\varepsilon$ sub-unit 4 (POLE4) (a subunit responsible for activation of replication and repair) might explain cross-resistance to fludarabine (Table 1) because of increased excision of fludarabine incorporated into DNA [33]. Hypersensitivity to docetaxel, 5-FU and cytarabine in $\mathrm{HaCaT}_{\mathrm{CDV}}$ could be mediated through up-regulation of influx transporters (SLC29A2; ENT2) or proteins involved in drug catabolism such as $C Y P 1 B 1$ and $C Y P 3 A 7$.

\section{Differential protein expression of MRP2, BCRP, P-gp and OAT1 transporters}

The differential expression of several transporters involved in multidrug-resistance [i.e. MRP2 ( $A B C C 2)$,
P-gp/MDR1 $(A B C B 1)$, BCRP $(A B C G 2)$ and OAT1 (SLC22A6)] was measured by Western blot. OAT1 was downregulated in $\mathrm{SiHa}_{\mathrm{CDV}}$ and $\mathrm{HeLa}_{\mathrm{CDV}}$ (2-fold) but not in $\mathrm{HaCaT}_{\mathrm{CDV}}$ (Figure 2A-2D). BCRP levels were increased in $\mathrm{SiHa}_{\mathrm{CDV}}$ but not in $\mathrm{HeLa}_{\mathrm{CDV}}$ and $\mathrm{HaCaT}_{\mathrm{CDV}}$ (Figure $2 \mathrm{~A}-2 \mathrm{D}$ ). MRP2 was only upregulated in $\mathrm{SiHa}_{\mathrm{CDV}}$ (Figure 2B-2D) while P-gp was not affected in any of the three $\mathrm{CDV}^{\mathrm{R}}$ cell lines (Figure 2C-2D).

The sensitivity of parental and $\mathrm{CDV}^{\mathrm{R}}$ cells to different MDR or P-gp inhibitors was then assessed (Figure S2). Zosuquidar and Tariquidar (P-gp inhibitors) as well as Reversan and MK-571 (MRP inhibitors) act as competitive inhibitors while verapamil and indomethacin are non-competitive inhibitors of MRP1. $\mathrm{SiHa}_{\mathrm{CDV}}$ showed hypersensitivity to reversan but not to MK-571. HeLa ${ }_{\mathrm{CDV}}$ displayed hypersensitivity to reversan and verapamil while $\mathrm{HaCaT}_{\mathrm{CDV}}$ showed hypersensitivity to tariquidar and indomethacin. 
We next evaluated CDV and HPMPA antiproliferative activities in presence of MDR or P-gp inhibitors to rule out differences in transport of purine and pyrimidine analogues (Figure $\mathrm{S} 3$ ). $\mathrm{SiHa} \mathrm{p}_{\text {parental }}$ was less sensitive to CDV and HPMPA in presence of the MRP inhibitor $\mathrm{MK}-571$. In $\mathrm{HeLa}_{\mathrm{CDV}}$, the HPMPA $\mathrm{CC}_{50}$ value was lower in presence of $4 \mu \mathrm{g} / \mathrm{ml}$ of zosuquidar than without inhibitor. The other inhibitors did not revert the resistant phenotype. These data point to some alterations of MDR and/or P-gp transporters in $\mathrm{SiHa}_{\mathrm{CDV}}$ and $\mathrm{HeLa}_{\mathrm{CDV}}$ cells but not in $\mathrm{HaCaT}_{\mathrm{CDV}}$.

\section{Intracellular CDV metabolism}

The impact of drug-resistance acquisition on CDV metabolism was analyzed to detect alterations in $\mathrm{CDV}$ activation by cellular kinases. In $\mathrm{SiHa}_{\mathrm{CDV}}$ cells, reduced amounts of CDV, CDV monophosphate (CDVp), CDV diphosphate (CDVpp) (the active drug form) and CDVp-choline were measured compared to $\mathrm{SiHa}_{\text {parental }}$ cells, but only the decrease in CDVp was statistically significant (Figure 3A). Interestingly, the incorporation of CDV into cellular DNA, measured after a drugexposure of $24 \mathrm{~h}$, was reduced by $50 \%$ in $\mathrm{SiHa}_{\mathrm{CDV}}$ cells $(p=0.0002)$ (Figure 3D). A more pronounced decrease in CDV activation was observed in $\mathrm{HeLa}_{\mathrm{CDV}}$ cells $(p<0.05$ for all four metabolites) (Figure 3B) and CDV incorporation into DNA was also reduced by $50 \%(p=0.0006)$.
In contrast, in $\mathrm{HaCaT}_{\mathrm{CDV}}$ cells, no significant differences with parental cells were measured for CDV metabolites while, for CDV incorporation into DNA, a decrease of $30 \%$ was observed (Figure 3C and 3D). Hence, each $\mathrm{CDV}^{\mathrm{R}}$ cell type exhibited a different pattern of CDV activation compared to parental counterpart.

\section{Levels of UMP/CMPK1 affect CTP and UTP synthesis}

After analyzing protein expression of several influx/efflux pumps in $\mathrm{CDV}^{\mathrm{R}}$ lines, we next measured the expression of UMP/CMPK1, the enzyme responsible for the first phosphorylation of CDV, in order to detect any possible impairment in the activation pathway of the drug. Parental SiHa and HeLa cells expressed 6-fold more $\mathrm{UMP} / \mathrm{CMPK} 1$ protein levels than the corresponding $\mathrm{CDV}^{\mathrm{R}}$ cells $(p<0.05)$ (Figure 4A). In contrast, the difference in UMP/CMPK1 expression between $\mathrm{HaCaT}_{\text {parental }}$ and $\mathrm{HaCaT}_{\mathrm{CDV}}$ was only of 1.4 -fold $(p=0.3679)$ (Figure 4B). For mitochondrial UMP/CMPK2, the fold-change between parental and $\mathrm{CDV}^{\mathrm{R}}$ cells was not statistically significant for any of the three cell lines.

The effects of changes on UMP/CMPK1 expression on CTP and UTP synthesis were investigated. CDP levels were significantly higher in parental cells than in $\mathrm{CDV}^{\mathrm{R}}$ $\mathrm{SiHa}$ and HeLa cells (3.4 to 3.7 fold-change) while in $\mathrm{HaCaT}$ cells, this difference was only of 1.7 (Figure 4C).
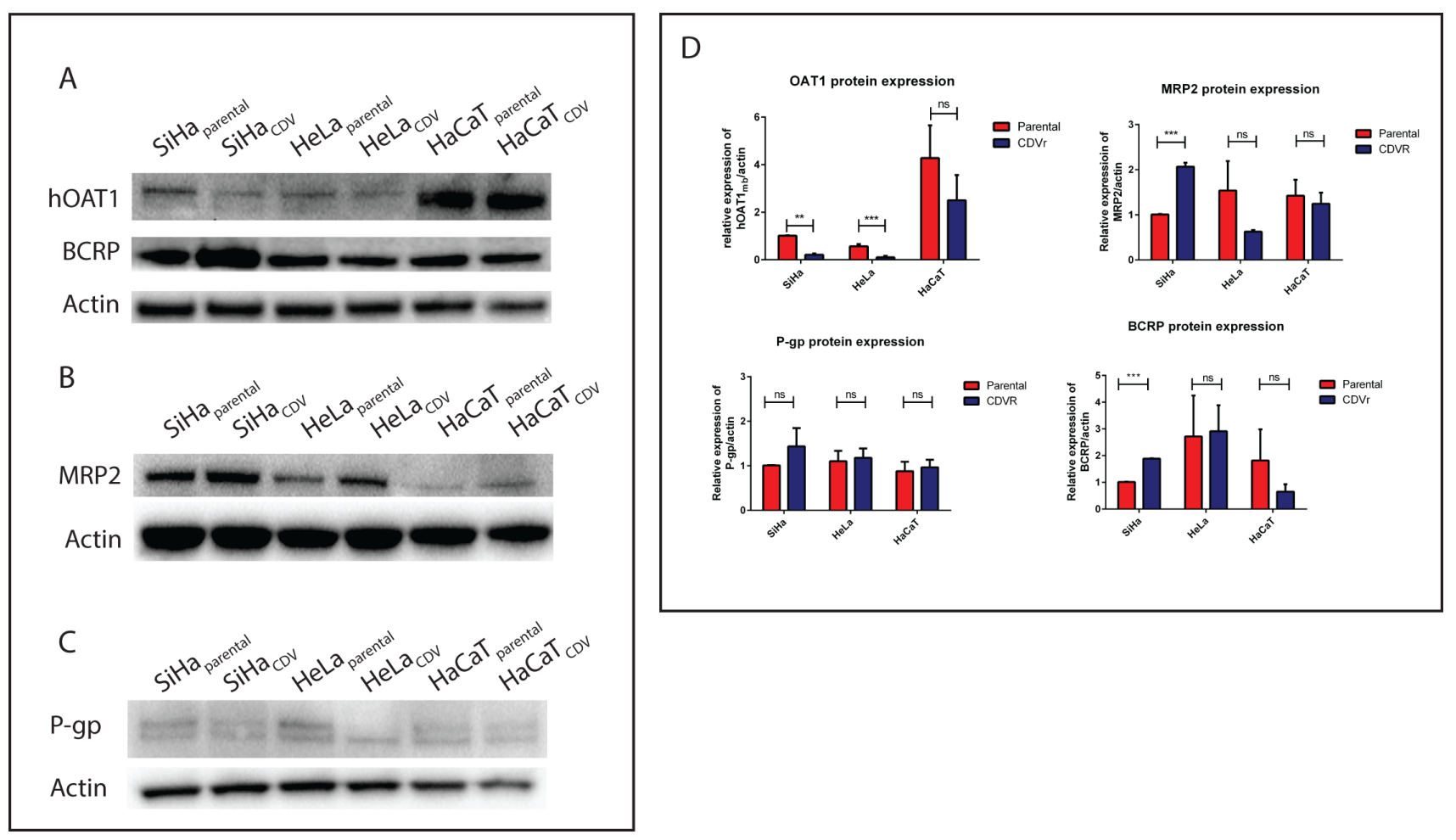

Figure 2: Differential expression of several ABC and SLC transporters. Western blot detection was performed to measure the levels of OAT1 and BCRP (A), MRP2 (B), and P-gp (C). Quantification of each band was done and standardized using actin as housekeeping gene (D). 
These results are in line with the lower levels of UMP/ CMPK1 in $\mathrm{SiHa}_{\mathrm{CDV}}$ and $\mathrm{HeLa}_{\mathrm{CDV}}$ cells but not in $\mathrm{HaCaT}_{\mathrm{CDV}}$ cells (Figure 4A-4B). In parallel, the levels of ATP and GTP were also measured in parental and $C^{2} V^{R}$ cell lines (Figure S4). ATP levels were not significantly affected, in the tested conditions, in the different cell lines (Figure S4A) while, regarding GTP levels, a significant increased level was only measured in $\mathrm{HaCaT}_{\mathrm{CDV}}$ cells compared to the parental counterparts (Figure S4B).

Since UMP/CMPK1 activity is impaired in $\mathrm{SiHa}$ and Hela $\mathrm{CDV}^{\mathrm{R}}$ cells, uridine (Urd) and cytidine $(\mathrm{Cyd})$ were added to the growth medium to restore CTP and UTP levels (Figure 4C). By supplementing the cells with $100 \mu \mathrm{M}$ of Urd and Cyd, the difference in CDP levels between parental and $\mathrm{CDV}^{\mathrm{R}}$ cells was abolished. Interestingly, the 4-fold lower CTP levels in $\mathrm{HeLa}_{\mathrm{CDV}}$ cells than in parental cells was reverted by the addition of Urd/Cyd. In $\mathrm{HeLa}_{\mathrm{CDV}}$ cells, accumulation of CMP in the presence of
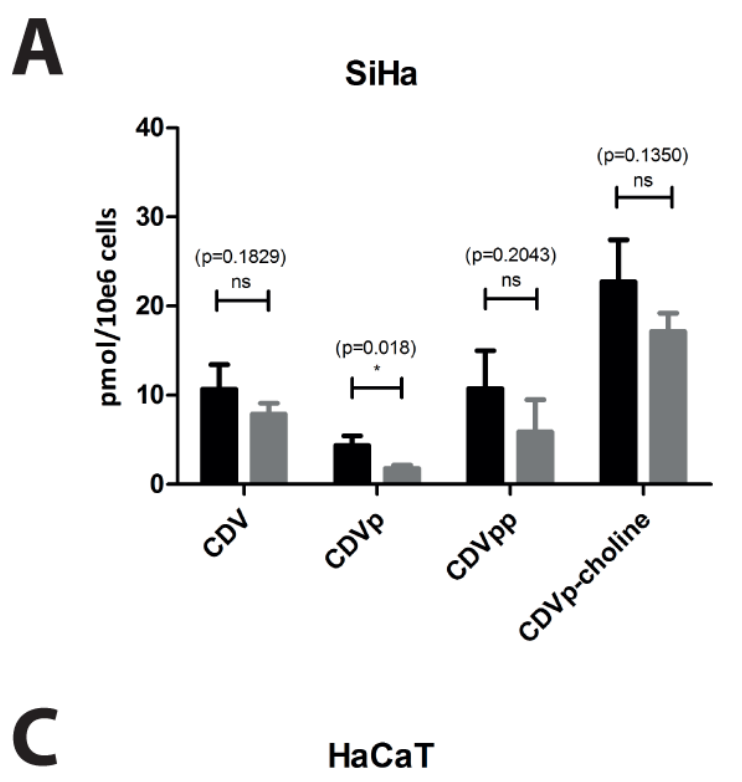

HaCaT

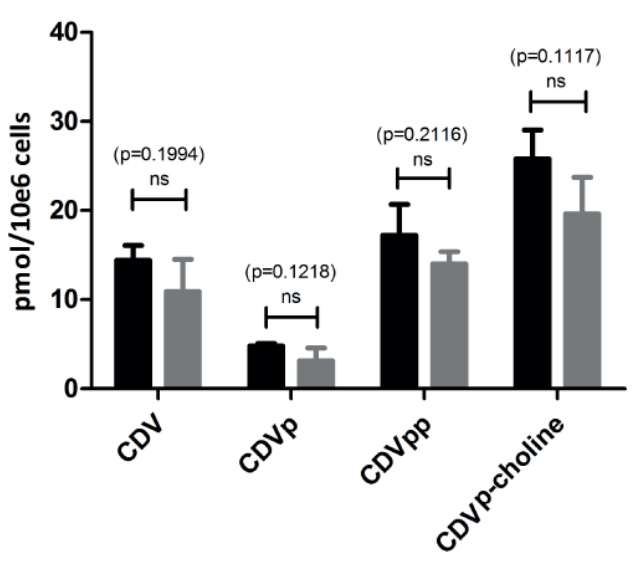

Urd/Cyd was found while there was barely any difference in CMP level for $\mathrm{HeLa}_{\text {parental }}$ cells with or without Urd/Cyd-supplements. Higher CTP levels in Urd/Cyd supplemented $\mathrm{HaCaT}_{\mathrm{CDV}}$ cells were observed than in the parental cells.

When radiolabeled Cyd and Urd were added to the cells and the levels of newly synthesized CTP and UTP were measured, CTP production was found to be higher in $\mathrm{SiHa}_{\text {parental }}$ than in $\mathrm{SiHa}_{\mathrm{CDV}}$ (5-fold and 6-fold difference at $6 \mathrm{~h}$ and $24 \mathrm{~h}$ post-treatment, respectively). For HaCaT and HeLa cells, the fold-changes in CTP production at $24 \mathrm{~h}$ were 1.9 and 0.9 , respectively (Figure 4D). These data confirm a more pronounced difference in CTP production between $\mathrm{SiHa}_{\mathrm{CDV}}$ and $\mathrm{SiHa}_{\text {parental }}$ cells than in the two other cell types. The UTP level variation seemed similar in the three cell types when measured at $24 \mathrm{~h}$ post-treatment (Figure 4D).

B

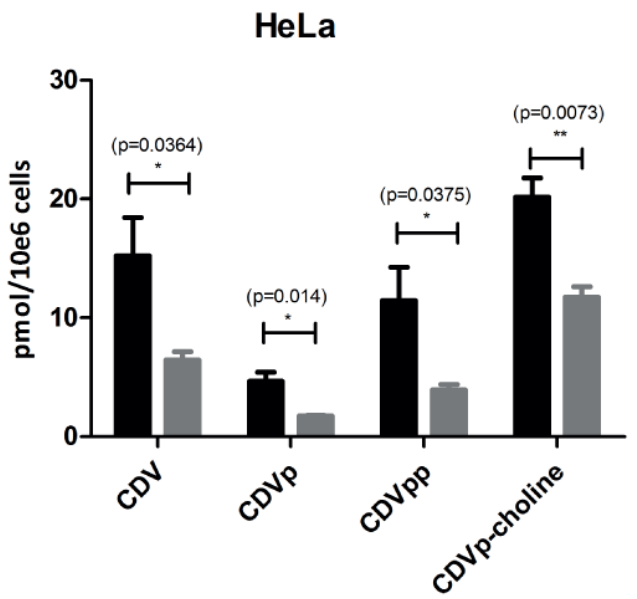

D

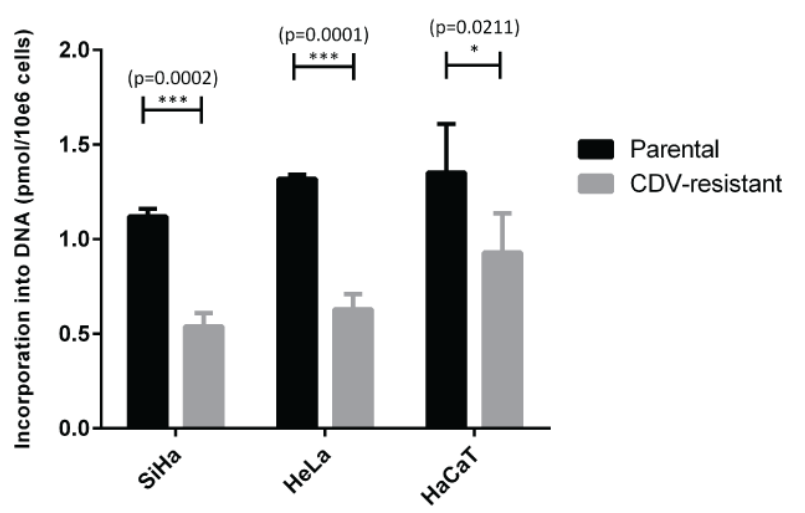

Figure 3: Intracellular metabolism of $\mathrm{CDV}$ in parental and $\mathrm{CDV}^{\mathrm{R}} \mathrm{SiHa}(\mathrm{A})$, HeLa (B) and HaCaT (C) cells. The intracellular levels of CDV, CDV monophosphate (CDVp), CDV diphosphate (CDVpp) and CDVp-choline have been measured using radiolabeled CDV. The mean values were calculated from at least three independent experiments. (D) The figure shows the incorporation of CDV into DNA for the three different cell types. The mean values have been calculated from two independent experiments. 


\section{Molecular basis for resistance to $\mathrm{CDV}$ : identification of mutations in UMP/CMPK1}

Two amino acid changes in the UMP/CMPK1 of $\mathrm{SiHa}_{\mathrm{CDV}}$ cells were identified (Figure S5): P64T [in the mobile nucleotide monophosphate (NMP) binding domain] and R134M [in the LID domain] (Figure S6). A mixed population of wild-type or double-mutated UMP/ CMPK1, or two single mutated UMP/CMPK1 were found. Unlike $\mathrm{SiHa}_{\mathrm{CDV}}$ cells, no mutations in UMP/CMPK1 were detected in $\mathrm{HeLa}_{\mathrm{CDV}}$ and $\mathrm{HaCaT}_{\mathrm{CDV}}$ cells. No mutations in the $U M P / C M P K 2$ gene were observed in the $\mathrm{CDV}^{\mathrm{R}}$ cells.
We also genotyped the two HPV oncogenes, i.e. E6 and E7, in $\mathrm{SiHa}_{\mathrm{CDV}}$ and $\mathrm{HeLa}_{\mathrm{CDV}}$ cells, but no differences were observed between parental and $\mathrm{CDV}^{\mathrm{R}}$.

\section{Enzymatic activity of recombinant UMP/CMPK1}

To investigate the impact of the mutations identified in the UMP/CMPK1 of $\mathrm{SiHa}_{\mathrm{CDV}}$ cells, site-directed mutagenesis was performed on a plasmid containing the coding sequence for UMP/CMPK1 to produce mutant enzymes carrying the P64T, R134M or a combination of both amino acid changes. The enzyme

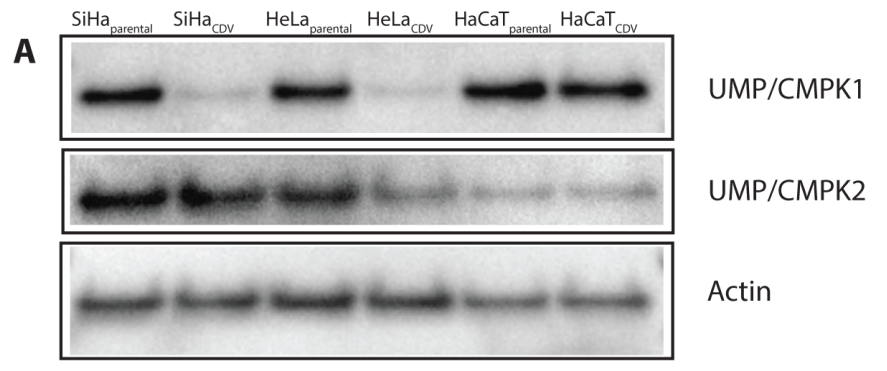

B

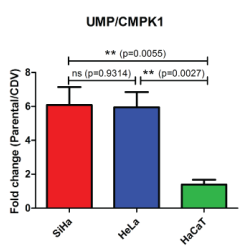

UMPICMPK2

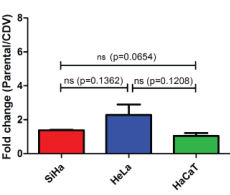

C
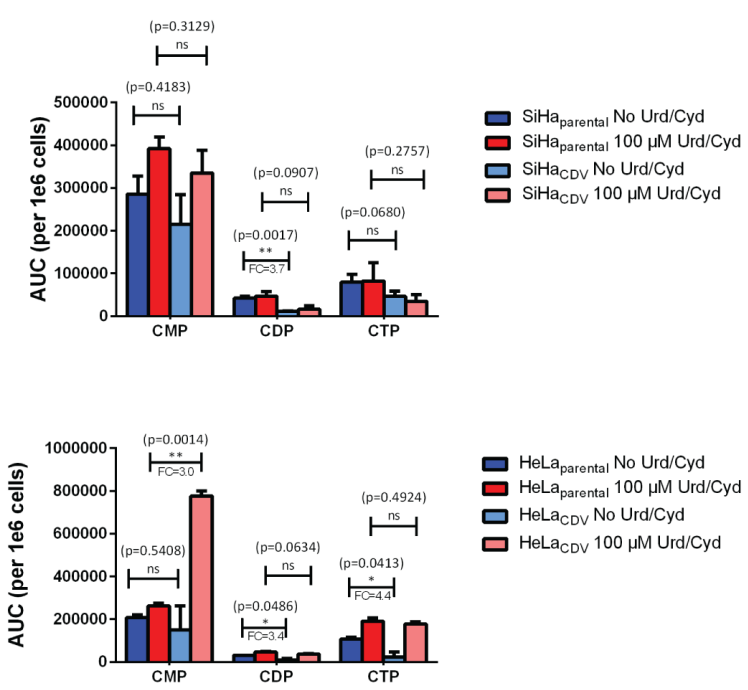

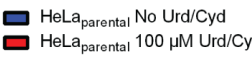
$\square \mathrm{HeLa}_{C D V}$ No Urd/Cyd $\square \mathrm{HeLa}_{\mathrm{CDV}} 100 \mu \mathrm{M}$ Urd/Cyd
D
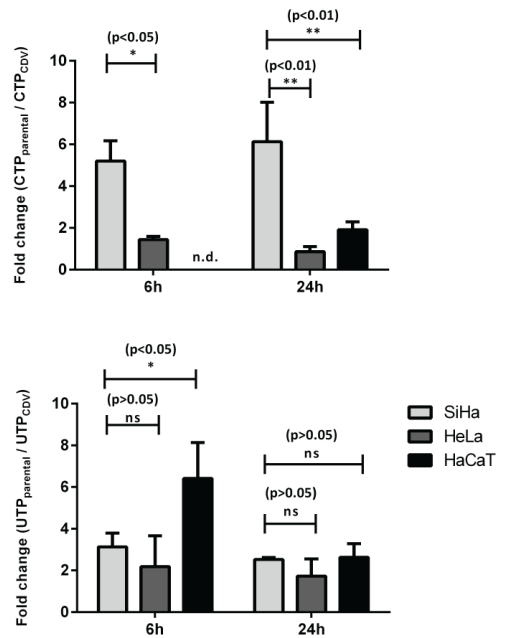

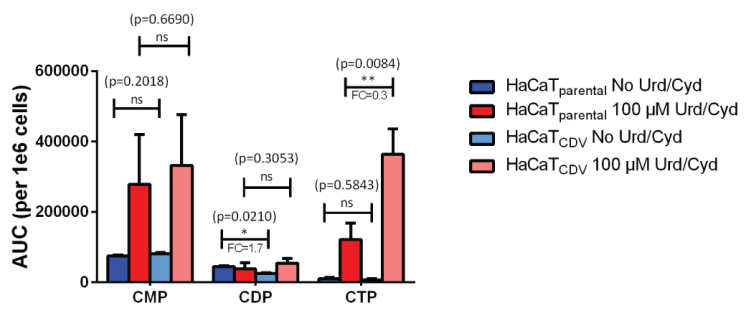

Figure 4: (A) Western blot detection of UMP/CMPK1 and 2 in the parental and CDV ${ }^{\mathrm{R}} \mathrm{SiHa}$, HeLa and HaCaT cells. (B) Fold-change (parental/CDV) of UMP/CMPK1 and 2 gene expression based on relative quantification compare to actin gene expression. The bars indicate the statistical difference between $\mathrm{SiHa}$, HeLa and HaCaT regarding UMP/CMPK1 downregulation. (C) Determination of CMP, CDP and CTP levels in parental and $\mathrm{CDV}^{\mathrm{R}}$ cells by HPLC. Fold change is indicated when the difference in level of nucleotides between the parental and the $\mathrm{CDV}^{\mathrm{R}}$ cell is statistically significant. (D) Ratio of parental over CDV ${ }^{\mathrm{R}}$ cells CTP and UTP levels determined by means of HPLC following radioactive cytidine and uridine supplementation. Radiolabeled nucleosides where added to the cell medium and CTP and UTP levels were measured after $6 \mathrm{~h}$ and $24 \mathrm{~h}$. No CTP level was detected in $\mathrm{HaCaT}_{\mathrm{CDV}}$ cells, preventing the comparison to the parental cells. 
bearing the P64T substitution had impaired enzymatic activity compared to the wild-type protein. Using CMP and UMP as phosphate acceptor, the turn-over number $k_{\text {cat }}$ was, respectively, $0.31 \mathrm{~s}^{-1}$ and $0.35 \mathrm{~s}^{-1}$ for the P64T mutant compared to, respectively, $125 \mathrm{~s}^{-1}$ and $188 \mathrm{~s}^{-1}$ for the wild-type enzyme (Table 2$)$. The affinity $\left(K_{\mathrm{M}}\right)$ for these substrates was also affected $\left(K_{\mathrm{M}}\right.$ values of $123 \mu \mathrm{M}$ and $250 \mu \mathrm{M}$ for, respectively, CMP and UMP with the P64T $\mathrm{UMP} / \mathrm{CMPK} 1$ mutant, instead of $20 \mu \mathrm{M}$ and $100 \mu \mathrm{M}$ with the wild-type enzyme). As a result, the catalytic efficiency $\left(k_{\text {cat }} / K_{\mathrm{M}}\right)$ for phosphorylation decreased in the range of 1,340- to 2,480-fold for the mutant P64T UMP/ CMPK1. The phosphorylation of dCMP and dUMP was also dramatically affected by the P64T substitution. dCMP was poorly phosphorylated by the P64T mutant, and dUMP was not metabolized at all under the experimental conditions used. The mutant P64T UMP/CMPK1 did not metabolize CDV and its 5-aza derivative (5azaCDV). The phosphorylation of these drugs by the wild-type enzyme was significantly slower than the rate seen for $\mathrm{dCMP}\left(k_{\text {cat }}\right.$ of $0.09 \mathrm{~s}^{-1}$ and $0.47 \mathrm{~s}^{-1}$, for CDV and 5azaCDV, respectively versus $13.4 \mathrm{~s}^{-1}$ ). On the contrary, cytarabine monophosphate (araCMP) was phosphorylated by the mutant enzyme but with a dramatic decrease of the catalytic rate $\left(k_{\text {cat }}=0.019 \mathrm{~s}^{-1}\right.$ and $K_{\mathrm{M}}=327 \mu \mathrm{M}$, instead of $k_{\text {cat }}=130 \mathrm{~s}^{-1}$ and $K_{\mathrm{M}}=315$ for wild-type enzyme).

The enzymes bearing the R134M amino acid change alone or in combination with the P64T, did not exhibit enzymatic activity with the natural substrates nor with CDV. The catalytic efficiencies obtained for the $\mathrm{UMP} / \mathrm{CMPK} 1$, could be ranked from the best acceptor substrate to the weakest, as follows: CMP > UMP > $\operatorname{araCMP}>\mathrm{dCMP}>\mathrm{dUMP}>5 \mathrm{azaCDV}>\mathrm{CDV}$ for the wild-type enzyme, and CMP $>\mathrm{UMP}>$ araCMP $\geq \mathrm{dCMP}$ for the mutant P64T enzyme. For the wild-type enzyme, the kinetic parameters obtained for the natural substrates were similar to those obtained in a previous study [15].

\section{Impact of point mutations on UMP/CMPK1 conformation and stability}

The effect of the two mutations on the stability of the UMP/CMPK1 protein was assessed by circular dichroism (CD). Far-UV CD spectra of wild-type UMP/CMPK1 without ligand showed the characteristic shape of a $\alpha$-helix-rich protein with minima at $208 \mathrm{~nm}$ and $222 \mathrm{~nm}$ and a maximum at $192 \mathrm{~nm}$. The CD spectrum of mutant P64T UMP/CMPK1 showed significant changes in the minima $208 \mathrm{~nm}$ and $222 \mathrm{~nm}$ but the overall shape is indicating a strong $\alpha$-helix content (Figure S7A). The effect of the amino acid change P64T is directly reflected on this $\alpha$-helix environment since the minima at $208 \mathrm{~nm}$ and $222 \mathrm{~nm}$ appeared to be changed in comparison to the wild-type enzyme. The ratio $[\theta]_{222} /[\theta]_{208}$ evolved from 1.006 to 0.809 , indicating a change in the folding of the
UMP/CMPK1 protein induced by the P64T amino acid change $(\theta$, being the degree of ellipticity).

The stability of the wild-type and the three mutant UMP/CMPK1 proteins was also investigated by thermal denaturation at two different temperatures (i.e. $5^{\circ} \mathrm{C}$ and $70^{\circ} \mathrm{C}$ ). Figure $\mathrm{S} 7 \mathrm{~B}$ shows the $\Delta \varepsilon$ at these temperatures for the wild-type and the three UMP/CMPK1 mutants. The P64T mutant started at a less native state compared to the wild-type protein, but at $70^{\circ} \mathrm{C}$, the enzyme was not totally unfolded. The R134M mutant was very sensitive to thermal denaturation and at high temperature, the denaturation state was comparable to that of the wild-type enzyme. The double mutant P64T + R134M was at an intermediate state between P64T and R134M (Figure S7B).

The R134M and P64T + R134M UMP/CMPK1 mutants are more sensitive to heat denaturation, suggesting that the P64T substitution triggers important conformational changes, higher stability of the enzyme and markedly impaired activity regarding the natural substrates CMP, UMP, dCMP and dUMP. The mutation $\mathrm{R} 134 \mathrm{M}$ totally inactivated the enzyme and, in addition, destabilized the secondary structure, leading to a temperature-sensitive protein.

\section{Modeling studies of the P64T and R134M amino acid changes}

Models of the human UMP/CMPK1 were built using as template the three-dimensional structure of the Dictyostelium discoideum UMP/CMPK in the closed conformation complexed with ADP and CMP (pdb code: 2UKD). The cytosine base interacts via water-mediated hydrogen bonds and hydrophobic interactions with residues Ile-62, Val-63 and Asn-97 (Figure 5A). Pro-64 is located next to Ile-62 and Val-63 and allows the positioning of these residues close to the cytosine moiety for the establishment of efficient interactions. The P64T substitution may modify the distance between Ile-62, Val-63 and CMP, and therefore reduce the intensity or abolish the interactions observed in the wild-type $\mathrm{UMP} / \mathrm{CMPK} 1$ at this position (Figure 5B). The Arg-134 is located in the LID domain, a mobile domain that contains positively charged residues able to stabilize the phosphate of the ATP with the magnesium ion in the active site (Figure 5C). The amino acid change Arg-to-Met at position 134 might dramatically decrease the number of polar interactions between the ATP and CMP molecules and the magnesium ion (Figure 5D). The typical interactions established between an arginine to bridge the phosphate of ATP and CMP for the enzymatic reaction are abolished in the presence of Met-134. As observed with the enzymatic studies, this mutation results in inactivation of the enzyme. The superposition between the open conformation of the human UMP/CMPK1 and the closed conformation of the Dictyostelium discoideum UMP/CMPK bound to CMP 
Table 2: Kinetic parameters $\left(\mathrm{k}_{\mathrm{cat}}, \mathrm{K}_{\mathrm{M}}\right.$ and $\left.\mathrm{k}_{\mathrm{cat}} / \mathrm{K}_{\mathrm{M}}\right)$ of the wild-type and the recombinant UMP/CMP kinases

\begin{tabular}{|c|c|c|c|c|c|c|c|c|c|c|c|c|}
\hline & \multicolumn{4}{|c|}{$\mathbf{k}_{\mathrm{cat}}\left(\mathrm{s}^{-1}\right)$} & \multicolumn{4}{|c|}{$\mathbf{K}_{\mathrm{M}}(\boldsymbol{\mu M})$} & \multicolumn{4}{|c|}{$\mathbf{k}_{\mathrm{cat}} / \mathbf{K}_{\mathrm{M}}\left(\mathbf{M}^{-1} \mathbf{s}^{-1}\right)$} \\
\hline & WT & P64T & R134M & \begin{tabular}{|c|} 
P64T \\
R134M
\end{tabular} & WT & P64T & R134M & \begin{tabular}{|c|} 
P64T \\
R134M
\end{tabular} & WT & P64T & $\mathrm{R} 134 \mathrm{M}$ & $\begin{array}{c}\text { P64T } \\
\text { R134M }\end{array}$ \\
\hline CMP & $125 \pm 20$ & $0.31 \pm 0.04$ & n.d. & n.d. & $20 \pm 5$ & $123 \pm 50$ & n.d. & n.d. & $6.25 \times 106$ & $2.52 \times 103$ & n.d. & n.d. \\
\hline UMP & $188 \pm 10$ & $0.35 \pm 0.10$ & n.d. & n.d. & $100 \pm 25$ & $250 \pm 25$ & n.d. & n.d. & $1.88 \times 106$ & $1.4 \times 103$ & n.d. & n.d. \\
\hline dCMP & $13.4 \pm 4.2$ & $0.036 \pm 0.010$ & n.d. & n.d. & $110 \pm 50$ & $970 \pm 220$ & n.d. & n.d. & $1.22 \times 105$ & 37 & n.d. & n.d. \\
\hline dUMP & $5.80 \pm 1.6$ & n.d. & n.d. & n.d. & $1034 \pm 250$ & n.d. & n.d. & n.d. & $5.61 \times 103$ & n.d. & n.d. & n.d. \\
\hline CDV & $0.09 \pm 0.04$ & n.d. & n.d. & n.d. & $2300 \pm 100$ & n.d. & n.d. & n.d. & 40 & n.d. & n.d. & n.d. \\
\hline 5azaCDV & $0.47 \pm 0.04$ & n.d. & n.d. & n.d. & $2080 \pm 250$ & n.d. & n.d. & n.d. & 226 & n.d. & n.d. & n.d. \\
\hline $\operatorname{araCMP}$ & $130 \pm 5$ & $0.019 \pm 0.007$ & n.d. & n.d. & $315 \pm 45$ & $327 \pm 30$ & n.d. & n.d. & $4.1 \times 105$ & 58 & n.d. & n.d. \\
\hline
\end{tabular}

Abbreviations: (n.d. not detected under our experimental conditions).

clearly shows that the helix $\alpha 4$ undergoes an important movement while closing the active site (Figure 5E). The residue at position 64 is located at the hinge, triggering this important conformational change and, consequently, an amino acid change at this specific position might have an important effect on the catalytic activity of the enzyme. This hypothesis is consistent with the kinetic parameters obtained with the mutant P64T UMP/CMPK1 that exhibited slower rates of phosphorylation for the natural substrates CMP, UMP and dCMP.

\section{DISCUSSION}

Emergence of drug-resistance after long-term exposure to antiproliferative agents is frequently observed in anticancer therapy. In general, drug-resistance can be related to several mechanisms including decreased uptake of the drug, slower drug-activation and faster drug-excretion via efflux pump(s). Studies of cytarabine and gemcitabine resistance mechanism have played an important role in the characterization of pyrimidine metabolism in tumor cells, but up to now, no description of resistance has been done regarding UMP/CMPK1. This is the first report of mutations in the UMP/CMPK1 linked to drug-resistance.

In $\mathrm{SiHa}_{\mathrm{CDV}}$ cells, two mutations were identified in the $\mathrm{CMPK} 1$ gene leading to low levels of UMP/CMPK1 protein. On the other hand, the reduced UMP/CMPK1 protein level in $\mathrm{HeLa}_{\mathrm{CDV}}$ was linked to down-regulation of $\mathrm{CMPK}$ l gene expression. In $\mathrm{HaCaT}_{\mathrm{CDV}}$, no changes in UMP/CMPK1 protein content were detected. These results are in line with impairment of CDV metabolism in $\mathrm{SiHa}_{\mathrm{CDV}}$ and $\mathrm{HeLa}_{\mathrm{CDV}}$ but not in $\mathrm{HaCaT}_{\mathrm{CDV}}$. These data highlight a different pattern of CDV metabolism in each $\mathrm{CDV}^{\mathrm{R}}$ cell lines and that reduction of UMP/CMPK1 protein level is not enough to explain $\mathrm{CDV}^{\mathrm{R}}$, since $\mathrm{HaCaT}_{\mathrm{CDV}}$ cells exhibited $\mathrm{CDV}^{\mathrm{R}}$ despite no impairment of UMP/CMPK1.

Reduced levels of UMP/CMPK1 in $\mathrm{SiHa}_{\mathrm{CDV}}$ resulted in poor CDV activation as shown by a significant decrease in CDVp but not in CDVpp or CDVp-choline. The enzymatic UMP/CMPK1 assay demonstrated that both amino acid changes (i.e. P64T and R134M) abolished the capacity of the enzyme to efficiently phosphorylate CDV. However, we did detect intracellular CDVp and the subsequent metabolites CDVpp and CDVp-choline in $\mathrm{SiHa}_{\mathrm{CDV}}$, suggesting that both wild-type and double mutant UMP/CMPK1s are expressed in these cells. The electropherograms of UMP/CMPK1 cDNA sequencing performed for $\mathrm{SiHa}_{\mathrm{CDV}}$ cells at passages 55 and 230 showed a mixed population of wild-type and mutant cells (1:1 ratio) at both positions (Figure S5). Thus, it can be inferred that both mutations are present in one allele and the other allele encodes for a wild-type enzyme. Co-existence of a mixed population of cells, one expressing exclusively wild-type enzyme and the other one expressing only mutant UMP/CMPK1, appears to be highly improbable since $\mathrm{SiHa}_{\text {parental }}$ cells have a faster growth rate and, hence, would overgrow $\mathrm{SiHa}_{\mathrm{CDV}}$ cells after several passages. Furthermore, the enzymatic study performed with mutant proteins showed that both P64T and R134M single mutations lead to impaired or non-functional enzymes while $\mathrm{SiHa}_{\mathrm{CDV}}$ cells were able to generate CTP from exogenous Cyd, UTP from added Urd, as well as CDVp and subsequent metabolites from CDV. Quantification of UMP/CMPK1 in $\mathrm{SiHa}_{\mathrm{CDV}}$ cells showed a dramatic decrease in the protein pool in comparison with parental cells. Protein stability assays showed that the P64T + R134M UMP/CMPK1 mutant is highly sensitive to temperature denaturation, and hence is an instable protein. Since the mutant enzyme is less stable, its intracellular half-life might be altered leading to faster degradation via the proteasome pathway. In conclusion, these data indicate that $\mathrm{SiHa}_{\mathrm{CDV}}$ cells most likely express both wild-type and mutant UMP/CMPK1.

The impact of altered UMP/CMPK1 expression on the activation of (d)C analogues might differ from cell to cell since it has been reported that modulation of UMP/ CMPK1 expression did not influence the activation of $\mathrm{C}$ and $\mathrm{U}$ analogues (dFdC, L-OddC and 5-FU) in RKO 

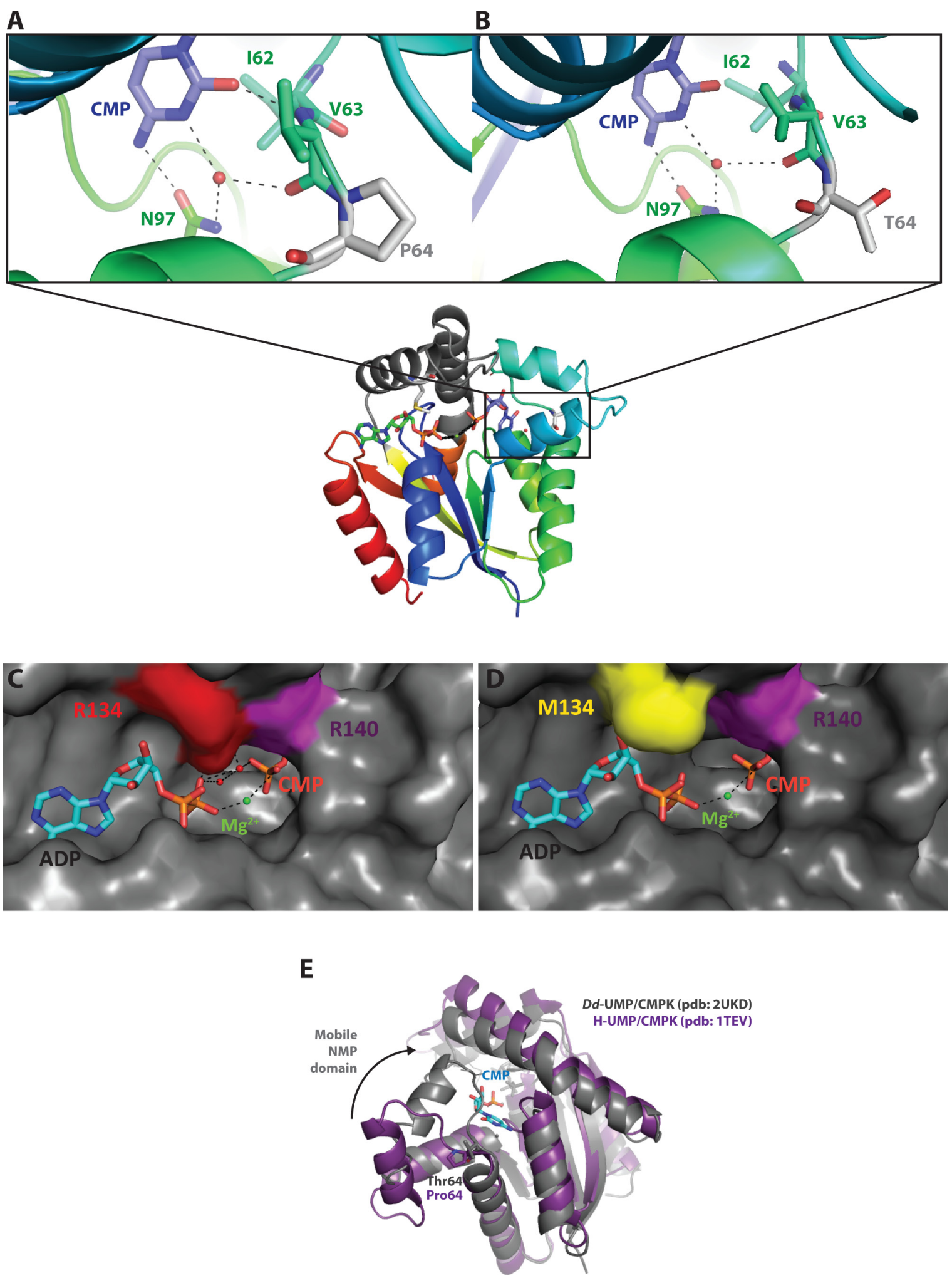

Figure 5: Structure-function relationship analysis of the mutant UMP/CMPK1s. (A-B) Comparison of the NMP binding site of WT and P64T UMP/CMPK1s complexed to CMP (in blue). Mutation at position 64 is represented as a grey residue. Amino acids in interaction with the base of CMP are depicted in green; the black dashes represent the polar interactions between the active site and CMP. (C-D) ATP binding site of WT and R134M UMP/CMPK1s with position 134 colored in red. ADP, bound to the active site, is colored in blue. Magnesium ion is represented as green sphere. The surface representation of the active site shows the steric hindrance of amino acid change R134M on ADP binding. (E) Superposition of the UMP/CMPK1 in open (in purple) and closed (in grey) conformation, showing the important movement that the NMP binding domain undergoes upon CMP binding. 
cells but well that of $2 \mathrm{FdC}$, araC and 5-FU in HeLa S3 and HCT8 cells $[34,35]$. In our study, we observed that genes related to metabolism of nucleoside analogues, such as CMPK1 and SLC29A1, were differentially expressed in $\mathrm{SiHa}_{\mathrm{CDV}}$ compared to $\mathrm{SiHa}_{\text {parental }}$ cells. However, these alterations were not linked to a drug-resistance phenotype such as gemcitabine-resistance. We cannot exclude that impairment of gemcitabine uptake and activation could be compensated by other transporters and enzymes (e.g. SLC 29A2 and CMPK2). Furthermore, no data for the cell lines here studied have been published yet describing the uptake and activation of cytarabine, gemcitabine and CDV.

In $\mathrm{HeLa}_{\mathrm{CDV}}$ cells, the total CDV metabolism seemed to be affected since not only the amount of CDVp was reduced but also CDV, CDVpp and CDVp-choline pools. The impairment in the whole metabolism of CDV might imply a role for the uptake or efflux considering the reduced amounts of intracellular CDV and CDVpp, resulting in a decreased CDV incorporation into the genomic DNA.

In $\mathrm{HaCaT}_{\mathrm{CDV}}$, no significant differences were observed regarding CDV metabolism and a small decrease in CDV incorporation into DNA was noted although a 58 -fold resistance to CDV was found. Thus, other events may be responsible for $\mathrm{CDV}^{\mathrm{R}}$ in these cells, such as alterations in CDV-targeted cellular pathways. The microarray analysis performed on parental and $C D V^{R}$ $\mathrm{HaCaT}$ cells showed that DNA repair mechanism(s) might also be responsible for $\mathrm{CDV}^{\mathrm{R}}$. The activation of these pathways might explain the resistance to CDV even if no significant impairment of the metabolism of this drug was registered. Furthermore, other cellular pathways (such as 'Wnt/ $\beta$-catenin signaling', 'ERK/MAPK signaling', 'EGF signaling', 'NFkB signaling' or 'acute phase response signaling') might have an effect on $\mathrm{CDV}^{\mathrm{R}}$ since several genes are differentially expressed in the $\mathrm{HaCaT}_{\mathrm{CDV}}$ compared to $\mathrm{HaCaT}_{\text {parental }}$.

The kinetic parameters obtained with the recombinant P64T UMP/CMPK1 enzyme with natural substrates indicated that the apparent affinity $K_{\mathrm{M}}$ was not dramatically affected. The main reason for the impaired phosphorylation of natural substrates for this mutant enzyme was the rate of catalysis since the $k_{\text {cat }}$ values were 403-, 537- and 372-fold slower for CMP, UMP and dCMP, respectively, than for the wild-type enzyme. The mobility of the NMP domain, induced by substrate binding to the active site, appears to play an important role in the catalysis reaction [36]. Substrate binding leads to displacement of $18 \AA$ of E59 carbon $\alpha$, a residue belonging to the NMP binding domain [37]. The P64 residue, located in the hinge, allows the NMP binding site main helices $(\alpha 3-\alpha 4)$ to change conformation in order to stabilize the closed conformation of the enzyme. The amino acid change P64T may alter this mobility, affecting the rate of phosphorylation by UMP/ CMPK1 of any phosphate acceptor.
Circular dichroism assays performed in thermal denaturing conditions demonstrated that the mutant P64T protein has a higher stability than the wild-type enzyme. By decreasing the mobility of the NMP domain, the P64T substitution may lead to a more compact protein. Even though the mutant enzyme acquires a higher stability, its enzymatic activity is dramatically impaired and CDV phosphorylation totally abolished.

The second affected position, R134, is located in the LID domain and is crucial for the activity of the UMP/CMPK1 enzyme since it interacts with ATP. The arginine to methionine change at the homologous position R132 in the human AMP kinase (that is structurally related to UMP/CMPK1) reduces the phosphorylation rate of AMP from $650 \mathrm{~s}^{-1}$ to $0.08 \mathrm{~s}^{-1}$ [38]. This conserved residue has an important role in the enzymatic activity of nucleoside monophosphate kinases, since it stabilizes the transition state for phosphate transfer between the two substrates. Circular dichroism analysis of the mutants bearing the R134M amino acid change revealed that the mutant protein has higher instability than the wild-type one, consistent with reduced protein levels.

Several multidrug-resistance proteins have been shown to be upregulated in $\mathrm{CDV}^{\mathrm{R}}$ cells. Regarding ANPs, MRP4, $-5,-7$ and -8 were shown to confer resistance to adefovir (PMEA); MRP4 is associated with resistance to PMEG, cPr-PMEDAP and PMEDAP; and overexpression of MRP5 confers resistance to PMEDAP [39-43]. Today, none of these transporters has been studied in the context of $\mathrm{CDV}^{\mathrm{R}}$, and we cannot exclude that upregulation of one of the MRPs might, in part, be responsible for $\mathrm{CDV}^{\mathrm{R}}$ in $\mathrm{SiHa}_{\mathrm{CDV}}, \mathrm{HeLa}_{\mathrm{CDV}}$ and $\mathrm{HaCaT}_{\mathrm{CDV}}$ cells. For instance, MRP2 is upregulated in $\mathrm{SiHa}_{\mathrm{CDV}}$, and $\mathrm{CDV}$ was shown to be both a substrate and an inhibitor of this transporter in primary tubular renal cells [44]. BCRP (ABCG2) was found upregulated in $\mathrm{SiHa}_{\mathrm{CDV}}$ while $\mathrm{P}$-gp might be associated with $\mathrm{HPMPA}^{\mathrm{R}}$ in $\mathrm{HeLa}_{\mathrm{CDV}}$, since zosuquidar, a known inhibitor of P-gp, decreased $\mathrm{CC}_{50}$ value for HPMPA (Figure S8), even if no upregulation of P-gp was seen in $\mathrm{HeLa}_{\mathrm{CDV}}$. These results suggest that altered levels of BCRP, MRP2 and P-gp transporters might contribute to $\mathrm{CDV}^{\mathrm{R}}$ in $\mathrm{SiHa}_{\mathrm{CDV}}$ and/or $\mathrm{HeLa}_{\mathrm{CDV}}$.

On the other hand, CDV uptake has been described to be mediated by SLC22A6-encoded OAT1 and higher protein levels of OAT1 were found in $\mathrm{SiHa}_{\text {parental }}$ and $\mathrm{HeLa}_{\text {parental }}$ which may reduce CDV uptake. However, since fluid-phase endocytosis has been described as the major mechanism of CDV uptake, and the expression of SLC22A6 genes is predominantly observed in renal cells, the impact of altered OAT1 expression on intracellular CDV pools might be very limited [45].

The impaired activity of the UMP/CMPK1 enzyme in the $\mathrm{SiHa}_{\mathrm{CDV}}$ and $\mathrm{HeLa}_{\mathrm{CDV}}$ cells could explain, at least in part, their reduced growth rate. Since the R134M change destabilizes the structure of UMP/CMPK1 leading to a 
reduced amount of protein, the decrease in intracellular UTP and CTP pools in resistant cells may be responsible, at least in part, for their slower growth rate. Similarly, doubling times of $\mathrm{HeLa}_{\text {parental }}$ and $\mathrm{HeLa}_{\mathrm{CDV}}$ cells were significant different suggesting an important role for UMP/ CMPK1 in cellular growth. In $\mathrm{HaCaT}_{\mathrm{CDV}}$, no significant decrease in UMP/CMPK1 protein level and no significant difference in growth rate were noted, even if $\mathrm{CDV}^{\mathrm{R}} \mathrm{HaCaT}$ cells appear to grow slightly faster than the parental counterpart. This might be the result of an increased GTP level in $\mathrm{HaCaT}_{\mathrm{CDV}}$ compared to $\mathrm{HaCaT}_{\text {parental }}$ cells.

$\mathrm{CDV}^{\mathrm{R}}$ seems to be acquired through alterations of CDV metabolism (i.e. impairment of UMP/CMPK1 activity) as well as MDR events (i.e. changes in expression of BCRP, MRP2 and OAT1) in SiHa and HeLa cells, indicating a multifactorial biochemical basis (Figure S8). On the other hand, in HaCaT cells, these factors were not found to be dramatically changed, suggesting that $\mathrm{CDV}^{\mathrm{R}}$ is mediated through an alternate mechanism that might involve genes linked to DNA damage response. In these cells, the levels of intracellular CDV metabolites were unaltered, further excluding the enzymes involved in CDV activation as responsible for the resistance phenotype.

One may wonder whether the presence of a partial HPV genome and the constitutive expression of E6 and E7 oncoproteins might influence drug-resistance acquisition, since both $\mathrm{SiHa}_{\mathrm{CDV}}$ and $\mathrm{HeLa}_{\mathrm{CDV}}$, in contrast to $\mathrm{HaCaT}_{\mathrm{CDV}}$ cells, underwent impairment of CDV activation and incorporation as well as alterations in the expression of drug transporters. Mutations in UMP/CMPK1 responsible for CDV-resistance have been selected and characterized in $\mathrm{HPV}(+)$ tumor cells and, to our knowledge, it is the first time that this enzyme has been involved in resistance against an antiviral or an anticancer drug, in vitro or in vivo. $\mathrm{Up}$ to now, no $\mathrm{CDV}^{\mathrm{R}}$ has been observed in patients receiving $\mathrm{CDV}$ for $\mathrm{HPV}$-associated diseases. Since UMP/CMPK1 is a key enzyme in the nucleoside salvage pathway, its activity cannot be substituted by another enzyme and therefore, the mutation-rate under drug-pressure might be very low. Hence, the high genetic barrier to $\mathrm{CDV}^{\mathrm{R}}$ may be considered as an asset for the use of this drug in cancer therapy. On the other hand, a low number of patients suffering from HPV-associated diseases (genital warts or laryngeal papillomatosis) shows an uncomplete response to CDV therapy. Genotyping of CMPK1 gene should be considered when CDV fails to clear $\mathrm{HPV}(+)$ cells in order to identify natural polymorphisms able to confer resistance to CDV.

The search for new drugs with anti-papillomavirus activity is urgently needed since, up to now, no chemotherapeutic agent has been brought to the market for the specific management of HPV-induced lesions. Although CDV has proven efficacious in the therapy of HPV-associated diseases, it has some limitations, the nephrotoxicity being the most encountered side-effect. Recent publications revealed some promising compounds such as the HIV-protease inhibitors lopinavir and nelfinavir, but further characterizations of their antiHPV activity are needed [46]. Also, inhibition of cellular pathways frequently altered in HPV-induced neoplasia, such as phosphatidylinositol-3-kinase signaling represent a suitable target for therapeutic intervention [47].

In conclusion, acquisition of resistance to $\mathrm{CDV}$ in tumor cell appears to be a multifactorial process and different mechanisms are involved in distinct cell lines. Importantly, we showed that alterations in UMP/CMPK1 may contribute to CDV-resistance in some cell lines.

\section{MATERIALS AND METHODS}

\section{Chemicals}

The list of the ANPs and chemotherapeutics used in this study is provided in Tables S1 and Figure S9. The source of other chemical reagents was as follows: Uridine (Urd) and adenosine-5'-triphosphate (ATP) Calbiochem; cytidine (Cyd), Valeant Pharmaceuticals; cytidine-5'-monophosphate (CMP), uridine-5'-monophosphate (UMP), 2'-deoxycytidine5'-monophosphate (dCMP) and 2'-deoxyuridine-5'monophosphate (dUMP), Sigma-Aldrich; arabinocytidine5'-monophosphate (araCMP), [5- $\left.{ }^{3} \mathrm{H}\right]$-radiolabeled CDV and $\left[5-{ }^{3} \mathrm{H}\right]$-uridine, Moravek Biochemicals; and $\left[5-{ }^{3} \mathrm{H}\right]-$ radiolabeled cytidine, MP Biochemicals.

\section{Selection of $C D V^{\mathrm{R}}$ cells and growth rate}

$\mathrm{SiHa}[\mathrm{HPV} 16(+)]$ and HeLa [HPV18(+)] cells were obtained from ATCC (\#HTB-35 and \#CCL-2, respectively) (Manassas, USA). HaCaT $[\mathrm{HPV}(-)]$ cells were kindly provided by F. De Marco (Regina Elena Institute for Cancer Research, Rome, Italy). Cell cultures were maintained in Dulbecco's modified Eagle's medium supplemented with $10 \%$ fetal calf serum. Selection of $\mathrm{HeLa}_{\mathrm{CDV}}$ and $\mathrm{HaCaT}_{\mathrm{CDV}}$ cells was performed as previously described for $\mathrm{SiHa}_{\mathrm{CDV}}$ cells [48]. The growth rate of $\mathrm{CDV}^{\mathrm{R}}$ cells compared to parental cells was evaluated as previously reported [48]. Doubling time (DT) was calculated with the formula: $\mathrm{DT}=\left(\mathrm{t}_{2}-\mathrm{t}_{1}\right) /\left(\log _{2} \mathrm{~N}_{2}-\log _{2} \mathrm{~N}_{1}\right)$, where $\mathrm{t}_{1}$ and $\mathrm{t}_{2}$ are the times at which the cells were counted, and $\mathrm{N}_{1}$ and $\mathrm{N}_{2}$ are the cells numbers at times $t_{1}$ and $t_{2}$.

\section{Microarray experiments}

Parental and $\mathrm{CDV}^{\mathrm{R}}$ cells were allowed to grow for $72 \mathrm{~h}$ in medium without CDV. Total RNA of $1 \times 10^{6}$ cells was isolated with TRIzol reagent (Invitrogen) and further purified by RNeasy Mini Kit (Qiagen). RNA quality and quantity were assessed with a Bioanalyzer system (Agilent). 
Microarray data were generated as previously reported [12] and is deposited in the Gene Expression Omnibus (GEO, http://www.ncbi.nlm.nih.gov/projects/ geo) according to MIAME standards under accession number GSE39293: http://www.ncbi.nlm.nih.gov/geo/ query/acc.cgi?acc $=$ GSE39293.

Bioinformatics analysis of differentially expressed (DE) genes was carried out with Ingenuity Pathways Analysis (IPA, Ingenuity ${ }^{\circledR}$ Systems) version 9 as previously reported [12].

\section{Antiproliferative activity}

Inhibition of cell growth was determined following 7 days of incubation with the assessed drug as previously described [49]. The antiproliferative effects were expressed as $\mathrm{CC}_{50}$ (50\% cystostatic concentration), which is the concentration required to reduce cell growth by $50 \%$ relative to the number of cells in untreated control cell culture). Fold-resistance (FR) was calculated as the ratio of $\mathrm{CC}_{50}$ for $\mathrm{CDV}^{\mathrm{R}}$ cells to $\mathrm{CC}_{50}$ for parental cells.

\section{Genotyping of UMP/CMPK1, UMP/CMPK2, HPV E6 and E7}

Total mRNA from parental and $\mathrm{CDV}^{\mathrm{R}}$ cells was isolated with the Quickprep mRNA purification kit (Amersham Biosciences) and converted to cDNA with the first-strand cDNA synthesis kit (GE Healthcare). The entire cDNA from each selected gene was amplified by PCR using specific primers. The PCR products were purified using PCR product purification kit (Roche) and directly sequenced using a cycle-sequencing kit (Dyenamic dye terminator kit; Amersham Biosciences), specific primers targeting both strands of the specific gene, and a capillary DNA sequencing system (MegaBACE 500; Amersham Biosciences). The data were assembled and compared to the DNA sequences obtained from reference sequences using Vector NTI software (Invitrogen). The primers used for the genotyping of UMP/CMPK1 and 2, and HPV oncogenes E6 and E7 are listed in Table S2.

\section{CDV metabolism}

$\left[5-{ }^{3} \mathrm{H}\right]$-radiolabeled CDV (Moravek) was used to assess the metabolism and drug incorporation into cellular nucleic acid material in parental and $\mathrm{CDV}^{\mathrm{R}}$ cells. The assay was performed with $10 \mu \mathrm{M}$ of CDV for $24 \mathrm{~h}$, a protocol adapted to the one described previously [12]. All experiments were performed in duplicate.

\section{Measurement of intracellular nucleotide levels}

To quantify the levels of CMP, CDP, CTP and UTP, semi-confluent parental and $\mathrm{CDV}^{\mathrm{R}}$ cells were grown in presence or absence of $100 \mu \mathrm{M}$ of uridine (Urd) and cytidine (Cyd) for $72 \mathrm{~h}$. Cells were trypsinized, collected by centrifugation, and subjected to cell lysis. To determine the nucleotide pools, the extracts were submitted to HPLC analysis on an anion exchange column [PartiSphere SAX column $(4.3 \mathrm{~mm} \times 125 \mathrm{~mm})$, Whatman] followed by UV spectroscopy. In parallel, $5 \mu \mathrm{Ci}$ per flask of radioactive $\left[5-{ }^{3} \mathrm{H}\right]$ labeled Urd or Cyd, supplemented in the growth medium of the parental and $\mathrm{CDV}^{\mathrm{R}}$ cells were used to investigate UTP and CTP biosynthesis at $6 \mathrm{~h}$ and $24 \mathrm{~h}$ after addition of the nucleosides.

\section{Site-directed mutagenesis of UMP/CMPK1}

The P64T, R134M and P64T/R134M changes were introduced in the pHL60-5 plasmid containing the UMP/CMPK1 gene with a three step protocol using the Quickchange Lightning Multi site-directed Mutagenesis kit (Agilent technologies ${ }^{\circledR}$ ). Primer(s) (Table S2) containing the base change(s) were used to perform a PCR reaction in order to produce mutant strands prior to enzymatic digestion of the template with $D p n$ I. To amplify the mutated plasmids, XL10 gold ultracompetent cells were transformed. Sequencing of the full UMP/CMPK1 gene from the recombinant plasmid was performed on both strands to exclude any additional mutation.

\section{Expression, purification and enzymatic activity measurement of recombinant UMP/CMPKs}

The wild-type and mutant UMP/CMPK1s were produced in Escherichia coli [strain BL21 Rosetta ${ }^{\circledR}$ (DE3) pLysS (Novagen)] as previously reported [14]. For protein purification, cells were broken by sonication and centrifuged for $30 \mathrm{~min}$ at $15,000 \mathrm{~g}$ and $4^{\circ} \mathrm{C}$. The supernatant was added onto a column containing $2 \mathrm{ml}$ Ni-Nitrilotriacetic acid resin (Ni-NTA) (Qiagen, Benelux). Protein elution was performed using increasing concentrations of imidazol and fractions were collected and pooled for dialysis. Protein purity was analyzed by polyacrylamide gel electrophoresis (SDS-PAGE) in denaturing conditions. The catalytic activity of the recombinant wild-type and mutant forms of human UMP/CMPK1 was determined using a previously described method [16] based on ADP formation [50].

\section{Circular dichroism}

All circular dichroism (CD) spectra measurements were acquired using a JOBIN-YVON CD6 spectropolarimeter as previously described [51]. CD measurements are reported as $\Delta \varepsilon\left(\mathrm{M}^{-1} \cdot \mathrm{cm}^{-1}\right)$. The relative helix content was deduced according to Zhong and Johnson as the percent of helix $=\left[\Delta \varepsilon_{222 \mathrm{~nm}} \times-10\right]$, where $\Delta \varepsilon_{222 \mathrm{~nm}}$ is the dichroic increment at $222 \mathrm{~nm}$ per residue [52]. Thermal denaturation curves of UMP/CMPK1s were obtained by monitoring $\Delta \varepsilon$ at $222 \mathrm{~nm}$ as a function 
of temperature from $0^{\circ} \mathrm{C}$ to $70^{\circ} \mathrm{C}$ with $10^{\circ} \mathrm{C}$ temperature steps. Experiments were performed in triplicate.

\section{Structural model for the amino acid changes in human UMP-CMPK1}

The role of the amino acid changes identified in the human UMP-CMPK1 in $\mathrm{SiHa}_{\mathrm{CDV}}$ cells was investigated by building a model of the enzyme complexed to ADP and CMP based on the published three-dimensional structure of the Dictyostelium discoideum UMP-CMPK (pdb code: 2UKD). Pymol Delano software was used to introduce the identified mutations and to visualize the generated models. A comparison of the open conformation of the human enzyme free of substrate (pdb code: 1TEV) and the closed conformation obtained by modeling was performed to predict the impact of the P64T mutation. All figures were generated using PyMol software.

\section{Western blot analysis}

UMP/CMPK1 and 2 were detected, respectively, using a mouse monoclonal antibody (ab77457) and a rabbit polyclonal antibody (ab103658) (Abcam, Cambridge, UK). Detection of the transporters P-glycoprotein (ab3083), MRP2 (ab3373), BCRP (ab130244) and OAT1 (ab118346) was performed on total cell membrane extracts with Plasma membrane protein extraction kit (ab65400). The house-keeping gene actin was detected using a mouse monoclonal antibody (ab3280). Species-specific HRP-conjugated secondary antibodies (Dako, Denmark) were used, in combination with Supersignal West Pico or Femto Chemiluminescent substrate (Thermo Scientific, Rockford, IL, USA)

\section{Statistical analysis}

Plotting and statistical analysis were performed using GraphPad software. The unpaired $t$-test was used to analyze several parameters between parental and $\mathrm{CDV}^{\mathrm{R}}$ cells (i.e. intracellular CDV metabolites, drug transporter protein levels, UMP/CMPK protein levels and drug-sensitivity). Comparison of CTP and UTP biosynthesis in parental and $\mathrm{CDV}^{\mathrm{R}}$ cells was carried out using the two-way analysis of variance test (two-way ANOVA). No correction for multiple testing was used due to the large number of statistical analyses performed. Data are presented as mean \pm standard deviation (SD) and $p<0.05$ was considered significant.

\section{ACKNOWLEDGMENTS}

We would like to thank Pierre Fiten, Steven Carmans, Sarah Gillemot, Lies van den Heurck, Anita Camps, Wim van Dam and Ria Van Berwaer for excellent technical assistance.

\section{FUNDING}

This study was supported by KU Leuven (GOA/15/019/TBA and PF no 10/18), by the Subvention for development of research organization RVO 61388963 and the grant 14-00522S by the Grant Agency of the Czech Republic.

\section{CONFLICTS OF INTEREST}

The authors declare that there are no conflicts of interest.

\section{REFERENCES}

1. Snoeck R, De Clercq E. Role of cidofovir in the treatment of DNA virus infections, other than CMV infections, in immunocompromised patients. Curr Opin Investig Drugs. 2002; 3:1561-1566.

2. Kirsch LS, Arevalo JF, Chavez dlP, Munguia D, De Clercq E, Freeman WR. Intravitreal cidofovir (HPMPC) treatment of cytomegalovirus retinitis in patients with acquired immune deficiency syndrome. Ophthalmology. 1995; 102:533-542.

3. Andrei G, Fiten P, Goubau P, van Landuyt H, Gordts B, Selleslag D, De Clercq E, Opdenakker G, Snoeck R. Dual infection with polyomavirus BK and acyclovir-resistant herpes simplex virus successfully treated with cidofovir in a bone marrow transplant recipient. Transpl Infect Dis. 2007; 9:126-131. doi: 10.1111/j.1399-3062.2006.00186.x.

4. De Clercq E. The clinical potential of the acyclic (and cyclic) nucleoside phosphonates: the magic of the phosphonate bond. Biochem Pharmacol. 2011; 82:99-109. doi: 10.1016/j. bcp.2011.03.027.

5. Snoeck R, Andrei G, Gerard M, Silverman A, Hedderman A, Balzarini J, Sadzot-Delvaux C, Tricot G, Clumeck N, De Clercq E. Successful treatment of progressive mucocutaneous infection due to acyclovir- and foscarnetresistant herpes simplex virus with (S)-1-(3-hydroxy-2phosphonylmethoxypropyl)cytosine (HPMPC). Clin Infect Dis. 1994; 18:570-578.

6. Snoeck R, Andrei G, De Clercq E. Specific therapies for human papilloma virus infections. Curr Opin Infect Dis. 1998; 11:733-737.

7. Hadaczek P, Ozawa T, Soroceanu L, Yoshida Y, Matlaf L, Singer E, Fiallos E, James CD, Cobbs CS. Cidofovir: a novel antitumor agent for glioblastoma. Clin Cancer Res. 2013; 19:6473-6483. doi: 10.1158/1078-0432.CCR-13-1121.

8. Liekens S, Verbeken E, De Clercq E, Neyts J. Potent inhibition of hemangiosarcoma development in mice by cidofovir. Int J Cancer. 2001; 92:161-167.

9. Neyts J, Sadler R, De Clercq E, Raab-Traub N, Pagano JS. The antiviral agent cidofovir [(S)-1-(3-hydroxy-2phosphonyl-methoxypropyl)cytosine] has pronounced activity against nasopharyngeal carcinoma grown in nude mice. Cancer Res. 1998; 58:384-388. 
10. Yang Y, Zhao X, Chen W, Gao Z, Liu A, Guo J, Yan Z, Dou Y, Wang H, Li Y. Effects of cidofovir on human papillomavirus-positive cervical cancer cells xenografts in nude mice. Oncol Res. 2010; 18:519-527.

11. Andrei G, Snoeck R, Schols D, De Clercq E. Induction of apoptosis by cidofovir in human papillomavirus (HPV)positive cells. Oncol Res. 2000; 12:397-408.

12. De Schutter T, Andrei G, Topalis D, Naesens L, Snoeck R. Cidofovir selectivity is based on the different response of normal and cancer cells to DNA damage. BMC Med Genomics. 2013; 6:18. doi: 10.1186/1755-8794-6-18.

13. Andrei G, Topalis D, De Schutter T, Snoeck R. Insights into the mechanism of action of cidofovir and other acyclic nucleoside phosphonates against polyoma- and papillomaviruses and non-viral induced neoplasia. Antiviral Res. 2015; 114C:21-46. doi: 10.1016/j.antiviral.2014.10.012.

14. Alexandre JA, Roy B, Topalis D, Pochet S, Perigaud C, Deville-Bonne D. Enantioselectivity of human AMP, dTMP and UMP-CMP kinases. Nucleic Acids Res. 2007; 35:48954904. doi: 10.1093/nar/gkm479.

15. Pasti C, Gallois-Montbrun S, Munier-Lehmann H, Veron M, Gilles AM, Deville-Bonne D. Reaction of human UMPCMP kinase with natural and analog substrates. Eur J Biochem. 2003; 270:1784-1790.

16. Topalis D, Kumamoto H, Amaya Velasco MF, Dugue L, Haouz A, Alexandre JA, Gallois-Montbrun S, Alzari PM, Pochet S, Agrofoglio LA, Deville-Bonne D. Nucleotide binding to human UMP-CMP kinase using fluorescent derivatives- a screening based on affinity for the UMPCMP binding site. FEBS J. 2007; 274: 3704-3714. doi: 10.1111/j.1742-4658.2007.05902.x.

17. Deville-Bonne D, El Amri C, Meyer P, Chen Y, Agrofoglio LA, Janin J. Human and viral nucleoside/ nucleotide kinases involved in antiviral drug activation: structural and catalytic properties. Antiviral Res. 2010; 86: 101-120. doi: 10.1016/j.antiviral.2010.02.001.

18. Van Rompay AR, Johansson M, Karlsson A. Phosphorylation of deoxycytidine analog monophosphates by UMP-CMP kinase: molecular characterization of the human enzyme. Mol Pharmacol. 1999; 56:562-569.

19. Xu Y, Johansson M, Karlsson A. Human UMP-CMP kinase 2, a novel nucleoside monophosphate kinase localized in mitochondria. J Biol Chem. 2008; 283: 1563-1571. doi: 10.1074/jbc.M707997200.

20. Liou JY, Dutschman GE, Lam W, Jiang Z, Cheng YC. Characterization of human UMP/CMP kinase and its phosphorylation of D- and L-form deoxycytidine analogue monophosphates. Cancer Res. 2002; 62:1624-1631.

21. Bouwman P, Jonkers J. The effects of deregulated DNA damage signalling on cancer chemotherapy response and resistance. Nat Rev Cancer. 2012; 12:587-598. doi: 10.1038/ nrc3342.

22. O'Connor R. The pharmacology of cancer resistance. Anticancer Res. 2007; 27:1267-1272.
23. Rosenzweig SA. Acquired resistance to drugs targeting receptor tyrosine kinases. Biochem Pharmacol. 2012; 83:1041-1048. doi: 10.1016/j.bcp.2011.12.025.

24. Galmarini CM, Mackey JR, Dumontet C. Nucleoside analogues: mechanisms of drug resistance and reversal strategies. Leukemia. 2001; 15:875-890.

25. Galmarini CM, Thomas X, Calvo F, Rousselot P, El Jafaari A, Cros E, Dumontet C. Potential mechanisms of resistance to cytarabine in AML patients. Leuk Res. 2002; 26: 621-629.

26. Cai J, Damaraju VL, Groulx N, Mowles D, Peng Y, Robins MJ, Cass CE, Gros P. Two distinct molecular mechanisms underlying cytarabine resistance in human leukemic cells. Cancer Res. 2008; 68:2349-2357. doi: 10.1158/0008-5472. CAN-07-5528.

27. Mata JF, Scrideli CA, Queiroz RP, Mori BO, Emerenciano M, Pombo-de-Oliveira MS, Tone LG. Cytosine arabinosidemetabolizing enzyme genes are underexpressed in children with MLL gene-rearranged acute lymphoblastic leukemia. Braz J Med Biol Res. 2006; 39:1417-1423.

28. Song JH, Kim SH, Kweon SH, Lee TH, Kim HJ, Kim HJ, Kim TS. Defective expression of deoxycytidine kinase in cytarabine-resistant acute myeloid leukemia cells. Int J Oncol. 2009; 34:1165-1171.

29. Connelly MC, Robbins BL, Fridland A. Mechanism of uptake of the phosphonate analog (S)-1-(3-hydroxy-2phosphonylmethoxypropyl)cytosine (HPMPC) in Vero cells. Biochem Pharmacol. 1993; 46:1053-1057.

30. Salphati L, Plise EG, Li G. Expression and activity of the efflux transporters $\mathrm{ABCB} 1, \mathrm{ABCC} 2$ and $\mathrm{ABCG} 2$ in the human colorectal carcinoma cell line LS513. Eur J Pharm Sci. 2009; 37:463-468. doi: 10.1016/j.ejps.2009.04.001.

31. Tiwari AK, Zhang R, Gallo JM. Overlapping functions of $\mathrm{ABC}$ transporters in topotecan disposition as determined in gene knockout mouse models. Mol Cancer Ther. 2013; 12:1343-1355. doi:10.1158/1535-7163.MCT-13-0100.

32. Zhang W, Shannon WD, Duncan J, Scheffer GL, Scheper RJ, McLeod HL. Expression of drug pathway proteins is independent of tumour type. J Pathol. 2006; 209:213-219. doi: 10.1002/path.1955.

33. Huang P, Chubb S, Plunkett W. Termination of DNA synthesis by 9-beta-D-arabinofuranosyl-2-fluoroadenine. A mechanism for cytotoxicity. J Biol Chem. 1990; 265:16617-16625.

34. $\mathrm{Hu} \mathrm{R}$, Lam W, Hsu CH, Cheng YC. UMP/CMPK is not the critical enzyme in the metabolism of pyrimidine ribonucleotide and activation of deoxycytidine analogs in human RKO cells. PLoS One. 2011; 6:e19490. doi: 10.1371/journal.pone.0019490.

35. Liou JY, Lai HR, Hsu CH, Chang WL, Hsieh MJ, Huang YC, Cheng YC. Modulation of human UMP/CMP kinase affects activation and cellular sensitivity of deoxycytidine analogs. Biochem Pharmacol. 2010; 79:381-388. doi: 10.1016/j. bcp.2009.09.010. 
36. Okajima T, Fukamizo T, Goto S, Fukui T, Tanizawa K. Exchange of nucleoside monophosphate-binding domains in adenylate kinase and UMP/CMP kinase. J Biochem. 1998; 124:359-367.

37. Segura-Pena D, Sekulic N, Ort S, Konrad M, Lavie A. Substrate-induced conformational changes in human UMP/CMP kinase. J Biol Chem. 2004; 279:33882-33889. doi: 10.1074/jbc.M401989200.

38. Dahnke T, Tsai MD. Mechanism of adenylate kinase. The conserved aspartates 140 and 141 are important for transition state stabilization instead of substrate-induced conformational changes. J Biol Chem. 1994; 269:8075-8081.

39. Dallas S, Schlichter L, Bendayan R. Multidrug resistance protein (MRP) 4- and MRP 5-mediated efflux of 9-(2-phosphonylmethoxyethyl)adenine by microglia. J Pharmacol Exp Ther. 2004; 309:1221-1229. doi: 10.1124/ jpet.103.063966.

40. Guo Y, Kotova E, Chen ZS, Lee K, Hopper-Borge E, Belinsky MG, Kruh GD. MRP8, ATP-binding cassette C11 (ABCC11), is a cyclic nucleotide efflux pump and a resistance factor for fluoropyrimidines $2^{\prime}, 3^{\prime}$-dideoxycytidine and 9'-(2'-phosphonylmethoxyethyl)adenine. J Biol Chem. 2003; 278:29509-29514. doi: 10.1074/jbc.M304059200.

41. Kruh GD, Zeng H, Rea PA, Liu G, Chen ZS, Lee K, Belinsky MG. MRP subfamily transporters and resistance to anticancer agents. J Bioenerg Biomembr. 2001; 33:493-501.

42. Lee K, Klein-Szanto AJ, Kruh GD. Analysis of the MRP4 drug resistance profile in transfected NIH3T3 cells. J Natl Cancer Inst. 2000; 92:1934-1940.

43. Sampath J, Adachi M, Hatse S, Naesens L, Balzarini J, Flatley RM, Matherly LH, Schuetz JD. Role of MRP4 and MRP5 in biology and chemotherapy. AAPS PharmSci. 2002; 4:E14. doi: 10.1208/ps040314.

44. Miller DS. Nucleoside phosphonate interactions with multiple organic anion transporters in renal proximal tubule. J Pharmacol Exp Ther. 2001; 299:567-574.
45. Connelly MC, Robbins BL, Fridland A. Mechanism of uptake of the phosphonate analog (S)-1-(3-hydroxy-2phosphonylmethoxypropyl)cytosine (HPMPC) in Vero cells. Biochem Pharmacol. 1993; 46: 1053-1057.

46. Hampson L, Martin-Hirsch P, Hampson IN. An overview of early investigational drugs for the treatment of human papilloma virus infection and associated dysplasia. Expert Opin Investig Drugs. 2015; 24:1529-1537. doi: 10.1517/13543784.2015.1099628.

47. Henken FE, Banerjee NS, Snijders PJ, Meijer CJ, De-CastroAJ, Rosl F, Broker TR, Chow LT, Steenbergen RD. PIK3CAmediated PI3-kinase signalling is essential for HPV-induced transformation in vitro. Mol Cancer. 2011; 10:71. doi: 10.1186/1476-4598-10-71.

48. De Schutter T, Andrei G, Topalis D, Duraffour S, Mitera T, van den Oord J, Matthys P, Snoeck R. Reduced tumorigenicity and pathogenicity of cervical carcinoma SiHa cells selected for resistance to cidofovir. Mol Cancer. 2013; 12:158. doi: 10.1186/1476-4598-12-158.

49. Andrei G, Snoeck R, Piette J, Delvenne P, De Clercq E. Antiproliferative effects of acyclic nucleoside phosphonates on human papillomavirus (HPV)-harboring cell lines compared with HPV-negative cell lines. Oncol Res. 1998; 10:523-531.

50. Blondin C, Serina L, Wiesmuller L, Gilles AM, Barzu O. Improved spectrophotometric assay of nucleoside monophosphate kinase activity using the pyruvate kinase/ lactate dehydrogenase coupling system. Anal Biochem. 1994; 220:219-221. doi: 10.1006/abio.1994.1326.

51. El Amri C, Martin AR, Vasseur JJ, Smietana M. Borononucleotides as substrates/binders for human NMP kinases: enzymatic and spectroscopic evaluation. Chembiochem. 2012 13:1605-1612. doi: 10.1002/ cbic. 201200199.

52. Zhong L, Johnson WC, Jr. Environment affects amino acid preference for secondary structure. Proc Natl Acad Sci U S A. 1992; 89:4462-4465. 